This document is the unedited Author's version of a Submitted Work that was subsequently accepted for publication in ACS Materials \& Interfaces, copyright (c) American Chemical Society after peer review.

To access the final edited and published work see [insert ACS Articles on Request author-directed link to Published Work, see https://pubs.acs.org/doi/10.1021/acsami.9b12566

\title{
Design and Tuning of the electrochemical properties of Vanadium-based cation disordered rock-salt oxide positive electrode material for lithium-ion batteries
}

Musa Ali Cambaz ${ }^{1}$, Bhaghavathi P. Vinayan ${ }^{1}$, Holger Euchner ${ }^{1,2}$, Syed Atif Pervez ${ }^{1}$, Holger Geßwein $^{3}$, Tobias Braun ${ }^{1}$, Axel Gross ${ }^{1,2}$, Maximilian Fichtner*1,3

${ }^{1}$ Helmholtz Institute Ulm for Electrochemical Energy Storage (HIU), Helmholtzstr. 11, 89081 Ulm, Germany

${ }^{2}$ Institute of Theoretical Chemistry,Ulm University, 89069 Ulm,Germany

${ }^{3}$ Institute for Applied Materials, Karlsruhe Institute of Technology, Herrmann-von-Helmholtz-Platz 1, D-76344 Eggenstein-Leopoldshafen, Germany

*Corresponding author's email address: $\underline{\text { m.fichtner@kit.edu }}$

Keywords: cation-disordered, vanadium, cathode, lithium-ion battery, mechanochemical synthesis, concentrated electrolyte, LiFSI, metal dissolution 


\begin{abstract}
Disordered rock-salt compounds are becoming increasingly important due to their potential as high capacity positive electrode materials for lithium-ion batteries. Thereby, a significant number of studies have focused on increasing the accessible $\mathrm{Li}$ capacity, but studies to manipulate the electrochemical potential are limited. This work explores the effect of transition metal substitution on the electrochemistry of ternary disordered rock-salt-type compounds with $\mathrm{LiM}^{2+}{ }_{0.5} \mathrm{~V}^{4+}{ }_{0.5} \mathrm{O}_{2}$ stoichiometry $(\mathrm{M}=\mathrm{Mn}, \mathrm{Fe}, \mathrm{Co})$. First-principles density functional theory study is used to predict the impact of the cation substitution on the expected average voltage. Moreover, the calculated electronic structures of these materials are used to analyze the underlying redox processes. Disordered rock-salt $\mathrm{Li}_{2} \mathrm{VO}_{3}$ involving a $\mathrm{V}^{5+/ 4+}$ redox couple with an average discharge voltage of $\sim 2.2 \mathrm{~V}$ has been reported previously. The introduced $\mathrm{LiM}^{2+}{ }_{0.5} \mathrm{~V}^{4+}{ }_{0.5} \mathrm{O}_{2}(\mathrm{M}=\mathrm{Mn}, \mathrm{Fe}, \mathrm{Co})$, formally depicted as a hypothetical solidsolution between " $\mathrm{Li}_{2} \mathrm{VO}_{3}-\mathrm{MO}$ ", can be used to rationalize the effect of cation substitution on their redox potential. The discharge voltages increase in the order of $\mathrm{Mn}<\mathrm{Fe}<\mathrm{Co}$ with 2.28, 2.41, $2.51 \mathrm{~V}$, exhibiting discharge capacities of 219,207 and $234 \mathrm{mAh} \mathrm{g}^{-1}$, respectively. Previous reports on vanadium-based disordered rock-salts show significant capacity fading during the cycling, and the reasons behind this capacity fading and its solutions have not been fully investigated. The current study shows that the use of a concentrated LiFSI electrolyte improves the cycling stability considerably by reducing the detrimental reactions. Finally, the presented compounds have been compared with state-of-the-art of vanadium-containing disordered rock-salt compounds in terms of energy density.
\end{abstract}




\section{Introduction}

The ever-growing importance to increase the energy density of lithium-ion batteries has impelled widespread research to develop novel high capacity electrode materials. Disputable, the lack of high capacity positive electrode materials, rather than the negative electrode, is limiting the overall energy density. ${ }^{1-3}$ Therefore, the development of new high-capacity positive electrode materials, which must offer long cycle life (preferably at low-cost) and at the same time be environmentally benign and non-toxic is of vital importance. ${ }^{4}$ Being a good lithium-ion conductor is an essential prerequisite for an intercalation host material to enable fast kinetics and high degree of lithiation/delithiation. As such, it needs percolating lithium sites spanning the structure, providing favorable and reversible lithium migration throughout the particles. ${ }^{5}$ Preserving the structural integrity with minor cation-mixing during charge-

discharge over a wide compositional range has been considered to be of great importance as cation-mixing was seen as highly detrimental for lithium-ion transport. This criterion has so far played a decisive role in the selection of suitable cations, which vary depending on the crystal structure. ${ }^{6,7} \mathrm{~A}$ widely employed approach by chemists consists of designing new materials by screening clusters of compounds with attractive structural features, which can provide framework structures feasible for hosting lithium-ions. ${ }^{8}$ Consistent with this understanding, the most common studied oxide-based positive cathode material are wellordered transition metal (TM) oxides like layered $\mathrm{LiMO}_{2}$, spinel-like $\mathrm{LiM}_{2} \mathrm{O}$, and $\mathrm{Li}_{2} \mathrm{M}_{2} \mathrm{O}_{4}$ (lithiated spinel) systems. ${ }^{1,9}$ On the contrary, cation-disordered rock-salt oxides have a long time been neglected as potential positive electrode materials. In particular $\alpha$-LiFeO -type ${ }_{2}$ structures, with lithium and the transition metal sharing the same site and being randomly distributed without long-range order have, due to the inherent disorder, been considered as unsuited. Cation-mixing between Li and transition metal sites can hinder sufficient percolation of the Li sites and thus impede the diffusion, leading to poor lithium conductivity 
and consequently to incomplete and irreversible lithium extraction/insertion. ${ }^{10}$ More recently it has been shown that disordered rock-salt oxides "can function well" for lithium-rich compositions with at least $9 \%$ lithium-excess. ${ }^{11}$ Decreasing the particle size and therefore shortening the diffusion pathways can also help to improve the accessible capacity. ${ }^{12}$ As a result, cation-disordered rock-salt materials have emerged as potential cathode materials and started to attract increasing interest. ${ }^{13-15}$ Several approaches to synthesize these materials have proven to be effective, in general comprising the introduction of lithium-excess into the host lattice. The first approach involves the introduction of lithium fluoride into the host lattice by a high energy mechanochemical approach. ${ }^{16}$ In this way, metastable compounds can be derived, which otherwise cannot be produced by solid-state synthesis. Fluoride anions can stabilize lower oxidation states and thus lower the average valence state as compared to oxides, which then allows for multiple oxidations and consequently higher capacity. ${ }^{17}$

Another approach, which has been widely adopted for the rational design of cation-disordered rock-salts, comprises the formation of a solid-solution between stoichiometric cationdisordered $\mathrm{LiMO}_{2}$ and high-valent $\mathrm{Li}$-rich compounds $\left(\mathrm{Li}_{2} \mathrm{MO}_{3}, \mathrm{Li}_{3} \mathrm{MO}_{4}, \mathrm{Li}_{4} \mathrm{MO}\right)_{5}{ }^{18}$ However, the small number of presently known stoichiometric cation-disordered rock salt oxides with $\alpha-\mathrm{LiFeO}_{2}$ crystal structure limits this option. Expanding the library of known rock-salt oxides would, therefore, be of great importance and may further push the development of this material class. First compounds have been identified, which have interesting electrochemical properties, but there are still open challenges and barriers to overcome, such as low rate capability, significant voltage slopes, and significant capacity fading.

Several factors have been determined to be critical for the cycling performance and degradation of the cell. These include, but are not limited to, structural changes and impedance build-up related to current collector corrosion, electrolyte decomposition and 
transition metal dissolution. ${ }^{19}$ Approaches to limit the metal dissolution are the stabilization of the structure by transition metal substitution ${ }^{20}$, surface modifications ${ }^{21,22}$, use of electrolyte additives $^{23}$ and optimized electrolyte formulations. ${ }^{24}$ Recently, lithium bis(fluorosulfonyl)imide (LiFSI) has been explored as a promising salt to improve the cycling stability and to replace $\mathrm{LiPF}_{6}$, as LiFSI is chemically more stable. ${ }^{25-28}$ However, the amide does not form stable passivation films, which results in severe anodic dissolution of the $\mathrm{Al}$ current collector for charging beyond $4 \mathrm{~V}$. Yamada et al. ${ }^{29,30}$ showed that Al dissolution can be inhibited for highly concentrated LiFSI electrolytes, which then enable the operation at $>4 \mathrm{~V}$ and moreover may alleviate transition metal dissolution due to the high molarity and higher viscosity.

Over the past decade, a significant number of studies have focused on enhancing the specific capacity of disordered rock salt materials; however, studies to fully understand and tune the electrochemical potential of these materials are very limited. We have recently proposed the disordered rock-salt type $\mathrm{LiNi} 0.5 \mathrm{~V}_{0.5} \mathrm{O}_{2},{ }^{31}$ ternary oxide as a potential positive electrode material for rechargeable lithium-ion batteries. In the present study, we aim to extend the number of disordered rock-salt type mixed vanadates by $\mathrm{LiM}_{0.5}^{+2} \mathrm{~V}_{0.52}^{+4} \mathrm{O}(\mathrm{M}=\mathrm{Fe}, \mathrm{Mn}, \mathrm{Co})$.

Here, we attempt to systemically study the effect of metal substitution in the ternary $\mathrm{LiM}_{0.5}^{+2} \mathrm{~V}_{0.52}^{+4} \mathrm{O}$ compounds, correlating our experimental findings with the electronic structure obtained from first-principles density functional theory (DFT). To the best of our knowledge, the herein presented oxide materials have not been reported as electrode materials before. Furthermore, we report on the impact of concentrated LiFSI electrolyte on the cycling stability of disordered rock-salt oxide electrodes. 


\section{Experimental Section}

\section{Synthesis:}

LNO-M compounds with a formal stoichiometry of $\mathrm{LiM}_{0.5} \mathrm{~V}_{0.5} \mathrm{O}_{2}(\mathrm{M}=\mathrm{Mn}, \mathrm{Fe}, \mathrm{Co})$ were synthesized by high-energy milling of stoichiometric amounts of $\mathrm{Li}_{2} \mathrm{O}, \mathrm{VO}_{2}$ and $\mathrm{MO}$ with M = Mn, Fe, Co for $20 \mathrm{~h}$ using a Fritsch P6 planetary ball mill with $80 \mathrm{~mL}$ silicon nitride vial and silicon nitride balls, with a ball to powder ratio of 20:1. All synthesis steps were carried out under inert gas atmosphere (Ar). VO has been synthesized by comproportionation of $1: 1$ $\mathrm{V} \mathrm{O}$ and $\mathrm{V} \mathrm{O} .{ }^{32} \mathrm{MnO}, \mathrm{CoO}, \mathrm{FeO}, \mathrm{Li} \mathrm{O}$ were purchased from Alfa Aesar with a purity $\geq$ $\begin{array}{lllll}2 & 3 & 2 & 5\end{array}$ 99.5\%. All steps have been taken under an exclusion to air and moisture.

\section{Electrolyte:}

5.5M LiFSI in dimethyl carbonate (DMC). Electrolyte solutions were prepared by mixing the appropriate quantity of LiFSI (Nippon shokubai) and DMC with battery grade. The obtained electrolyte is a clear solution. LP30 from BASF (ethylene carbonate/ dimethyl carbonate, 1:1 weight ratio with $1 \mathrm{M} \mathrm{LiPF}_{6}$ was used as an electrolyte.

\section{Materials Characterizations:}

Synchrotron X-ray powder diffraction (XRPD) experiments were performed at the SwissNorwegian Beamline (SNBL), beamline BM01, at the European Synchrotron Radiation Facility (ESRF). The powdered samples were filled in $0.5 \mathrm{~mm}$ quartz capillaries and sealed with wax under an argon atmosphere. XRPD data were collected using a PILATUS 2M area detector from DECTRIS, a sample-to-detector distance of $142.27 \mathrm{~mm}$, beam size of $0.2 \times 0.2$ $\mathrm{mm}$, a wavelength of $0.68202 \AA$, a $20^{\circ}$ rotation of the capillary and an exposure time of $20 \mathrm{~s}$. The data were converted to conventional one-dimensional powder patterns using the FIT2D software ${ }^{33}$ In-house X-ray powder diffraction data were collected under rotation of the capillary on an STOE Stadi P diffractometer with Mo K $\alpha 1(\lambda=0.7093 \AA)$ using Debye- 
Scherrer geometry. The powder samples were sealed in quartz capillary $(0.5 \mathrm{~mm}$ in diameter $)$ under an argon atmosphere.

The scanning electron microscope (SEM) and energy-dispersive X-ray spectroscopy (EDS) was carried out using the instrument LEO GEMINI 1550 VP equipped with Silicon Drift Detector (OXFORD Instruments). TEM investigations were performed on Tecnai F20ST transmission electron microscope operated at 200kV. Brunauer-Emmett-Teller (BET) surface area analyses of the samples were performed with a Micromeritics ASAP 2020 MP system.

\section{Electrochemical Measurements:}

Electrochemical tests were carried out in Swagelok-type cell versus lithium metal as reference and counter electrode. Electrode slurries were made of $90 \mathrm{wt} . \%$ composite and 10wt.\% polyvinylidene difluoride (PVDF) binder with N-methyl-2-pyrrolidone (NMP) as the solvent. The composite consists of active material and Super C65 carbon black in a weight ratio of 80:20. The mixed slurry was coated on an aluminum foil by doctor blade technique and dried at $120^{\circ} \mathrm{C}$ for $12 \mathrm{~h}$ under vacuum. Each working electrode $(12 \mathrm{~mm}$ diameter) contained approximately $3 \mathrm{mg}$ of active material, and Li foil was used as a counter electrode. Cyclic voltammetry (CV) experiments for the cells have been carried out from 1.3 to $4.5 \mathrm{~V}$ at various scan rates $0.05-0.5 \mathrm{mVs}^{-1}$ using a Bio-Logic VMP-3 potentiostat at the room temperature. Temperature controlled galvanostatic charge-discharge experiments were conducted at $25^{\circ} \mathrm{C}$ in climate chambers using an Arbin electrochemical workstation.

Conductivity: To measure the conductivity, the powders of materials were pressed into pellets with a diameter of $8 \mathrm{~mm}$ and coated with gold on both sides by sputtering. AC impedance data were collected in the frequency range $0.1 \mathrm{~Hz}$ to $1 \mathrm{MHz}$ (amplitude $10 \mathrm{mV}_{\mathrm{rms}}$ ) using a frequency response analyzer (ZAHNER-Elektrik $\mathrm{GmbH}$ ) at various temperatures $\left(25^{\circ}-80{ }^{\circ} \mathrm{C}\right)$. After each temperature, the samples were allowed to equilibrate for a substantial 
amount of time. The impedance data were analyzed using the ZMAN 2 program and fitted with an 'Equivalent Circuit'.

\section{Theoretical calculations:}

The periodic density functional theory (DFT) code VASP was applied for an investigation of stability and electronic structure of different Li2MVO4 compounds (with $\mathrm{M}=\mathrm{Mn}, \mathrm{Fe}, \mathrm{Co}$ ).

While the PBE functional was used to account for exchange and correlation, the electron-ion interaction was described by the projector augmented wave (PAW) method. Moreover, to take the localization of d-electrons into account, the GGA+U correction was applied for $\mathrm{Ni}, \mathrm{V}$ and (Ni 6.0, V 3.1, following the choice of Urban et al. ${ }^{34}$ To computationally access the disordered rocksalt structure of these compounds, the special quasi-random structure approach was applied for the construction of supercells corresponding to the stoichiometry $\mathrm{Li}_{16} \mathrm{M}_{8} \mathrm{Ni}_{8} \mathrm{O} 32$.

These supercells were optimized with respect to cell volume and atomic positions. For this purpose, a 5x5x5 k-point mesh, using the Monkhorst-Pack scheme, was chosen in combination with a cutoff energy of $600 \mathrm{eV}$. In the next step, the structures were delithiated and also optimized, using the same settings. From the total energies of the lithiated and delithiated structures as well as bulk $\mathrm{Li}$, the corresponding average voltage was then calculated.

\section{Results and Discussion}

\section{Structural Characterizations}

The quaternary disordered rock-salt vanadates $\mathrm{LiM}_{0.5} \mathrm{~V}_{0.5} \mathrm{O}_{2}(\mathrm{M}=\mathrm{Fe}, \mathrm{Mn}, \mathrm{Co})$ can be prepared through a direct one-step mechanochemical approach. Figure 1 shows the X-ray powder diffraction pattern (XRPD) with the corresponding Rietveld refinement confirming the cationdisordered rock-salt structure. For a single-phase fit with cubic $F m-3 m$ symmetry, the lattice constants were estimated as LiMn0.5 $\mathrm{V}_{0.5} \mathrm{O}_{2}: a=4.1996(8) \AA \mathrm{LiFe}_{0.5} \mathrm{~V}_{0.5} \mathrm{O}_{2}: a=4.1460(4) \AA$ 
and $\operatorname{LiCo} 0.5 \mathrm{~V}_{0.5} \mathrm{O}_{2}: a=4.1608$ (5) $\AA$. Transmission electron microscopy (TEM) images (see Figure S1 in the supplementary) show the typical morphology ${ }^{35}$ for mechanochemically synthesized compounds with irregular shaped, agglomerated secondary particles consisting of 20-100 nm-sized crystallites. The elemental mappings of $\mathrm{LiM}_{0.5} \mathrm{~V}_{0.5} \mathrm{O}_{2}(\mathrm{M}=\mathrm{Fe}, \mathrm{Mn}, \mathrm{Co})$ and the scanning electron microscopy images are presented in Figure S2-S4, respectively.
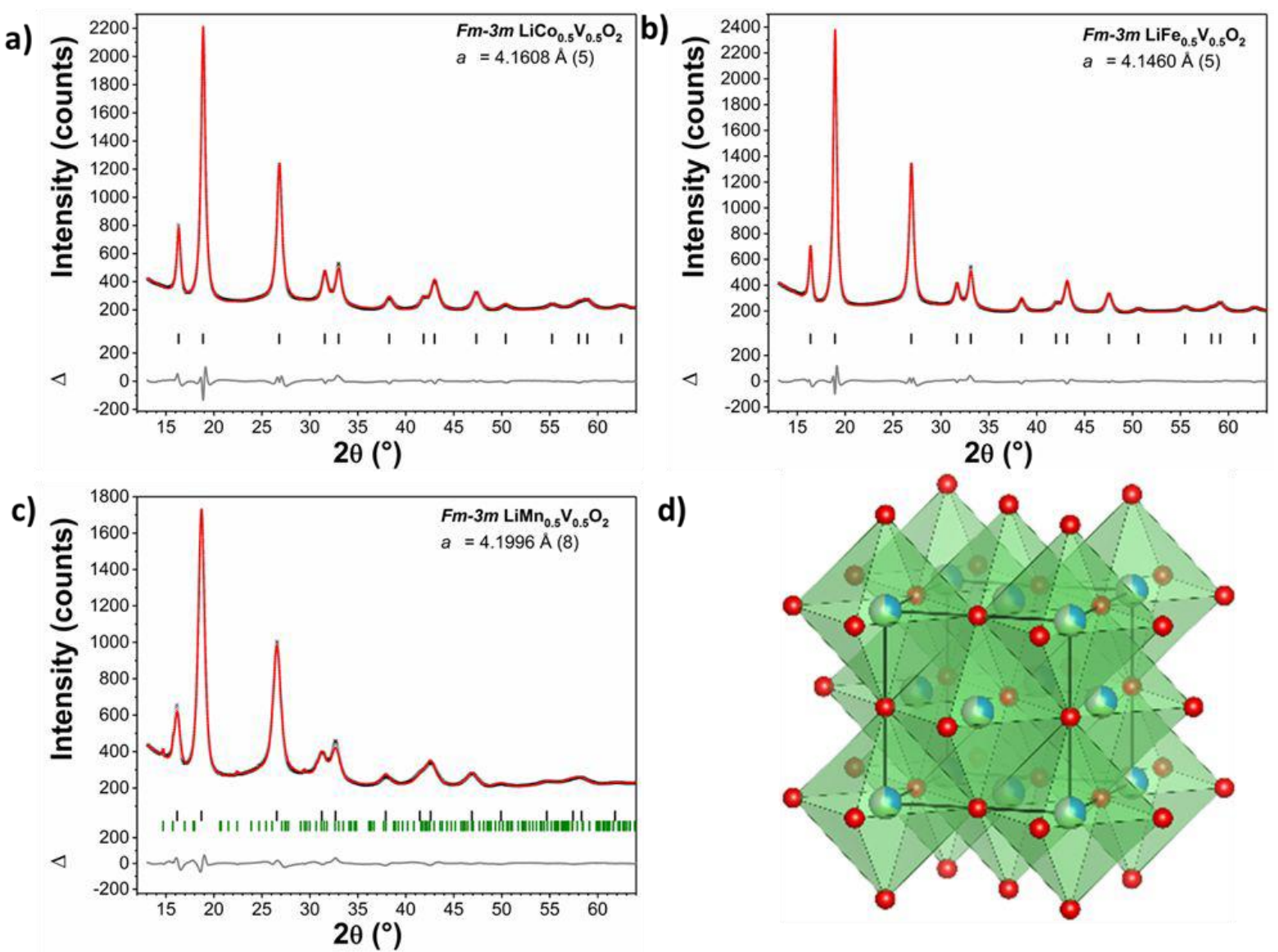

d)

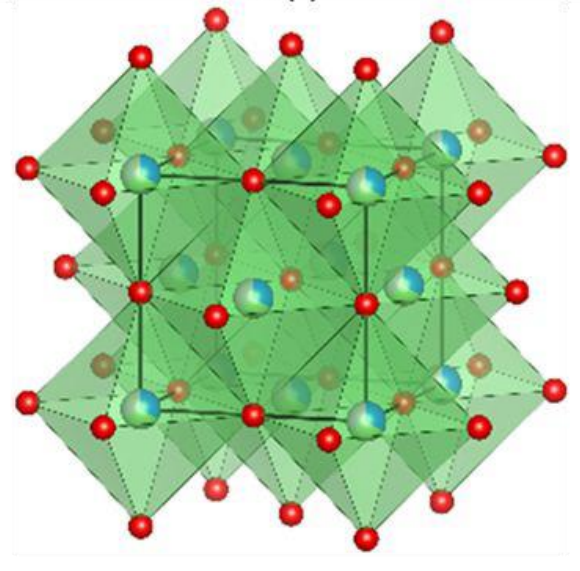

Figure 1: X-ray diffraction patterns with the corresponding fit obtained by Rietveld refinement for a) $\mathrm{LiCo0.5} \mathrm{V}_{0.5} \mathrm{O}_{2}$, b) $\mathrm{LiFe} 0.5 \mathrm{~V}_{0.5} \mathrm{O}_{2}$ and c) $\mathrm{LiMn}_{0.5} \mathrm{~V}_{0.5} \mathrm{O}_{2}$. d) shows a schematic crystal structure ${ }^{14}$ of $\mathrm{LiM}_{0.5} \mathrm{~V}_{0.5} \mathrm{O}_{2}$ with cubic unit cell and cations randomly occupying the octahedral sites.

\section{Density functional theory calculations}

Density functional theory (DFT) calculations with the periodic DFT code VASP ${ }^{36}$ were conducted to elaborate the differences in stability and electronic structure of the 
experimentally investigated $\mathrm{LiM}_{0.5} \mathrm{~V}_{0.5} \mathrm{O}_{4}$ compounds (with $\mathrm{M}=\mathrm{Mn}, \mathrm{Fe}, \mathrm{Co}$ ). In our calculations, the PBE functional ${ }^{37}$ was used to account for exchange and correlation, while the electron-ion interaction was described by the projector augmented wave (PAW) method. ${ }^{38}$ To account for the localization of d-electrons that is typically evidenced in transition metal oxides, the Hubbard-like U correction was considered for V, Mn, Fe and Co (V $3.1 \mathrm{eV}, \mathrm{Mn} 3.9 \mathrm{eV}$, Co $3.4 \mathrm{eV}, \mathrm{Fe} 4.0 \mathrm{eV}$ ), following references. ${ }^{10,39}$

For electronic structure calculations, the disorder is still a difficult task to cope with. In this work, we use the so-called special quasi-random structure (SQS) approach ${ }^{39}$ to treat the disorder in the DRS structures of the investigated compounds. For this purpose, we have constructed $2 \times 2 \times 2$ supercells of $\mathrm{LiM}_{0.5} \mathrm{~V}_{0.5} \mathrm{O}_{2}$ stoichiometry and then were fully optimized with respect to both volume and atomic positions. For the structural optimization, a $5 \times 5 \times 5$ k-point mesh and an energy cutoff of $600 \mathrm{eV}$ were selected. Delithiated structures were constructed by complete removal of Li and subsequently optimized with the previously described settings. The total energies of lithiated and delithiated $\mathrm{Lix}_{\mathrm{x}} \mathrm{M}_{0.5} \mathrm{~V}_{0.5} \mathrm{O}_{2}$ (with $\mathrm{x}=0$ or $\mathrm{x}=1$ ), in combination with that one of bulk $\mathrm{Li}$, were then used to calculate the average voltages of these cathode materials. The calculations indeed reproduce the experimentally observed trends and show a decreasing voltage from Co to Mn (Co $3.18 \mathrm{~V}, \mathrm{Fe} 3.10 \mathrm{~V}$, Mn $2.98 \mathrm{~V}$ ). For an investigation of the redox activity in these materials, the electronic density of states (DOS) for the fully lithiated structures (LiM V O stoichiometry) were calculated. 0.50 .52

The partial DOS for transition metal d-electrons and oxygen p-electrons were extracted and are plotted in Figure 2. As previously evidenced for Ni-based quaternary oxides ${ }^{31}$, we also find a strong contribution of the oxygen p-states close to the Fermi level. However, in contrast to the Ni-based oxides, the here investigated $\mathrm{Li}_{x} \mathrm{M}_{0.5} \mathrm{~V}_{0.5} \mathrm{O}_{2}$ compounds show a strong hybridization of the oxygen p- with the $\mathrm{V}$ d-orbitals, which means that less anionic redox and, hence, smaller tendencies for oxygen release can be expected under delithiation. Interestingly, the d-states of the additional transition metals ( $\mathrm{Mn}, \mathrm{Fe}, \mathrm{Co})$ also show contributions directly 
below the Fermi level. In fact, the Fe d-states even show a strong peak at the same energy than the V d-states, such that under delithiation Fe and V may be oxidized at the same time. In case of the Co and Mn compounds, the $\mathrm{V}$ d-states are dominant directly below $\mathrm{E}_{\mathrm{F}}$, thus indicating that $\mathrm{V}$ will be oxidized first. Nevertheless, there are already small contributions of the Mn d-states visible below $\mathrm{E}_{\mathrm{F}}$ and, notably, a large Co peak only slightly below the $\mathrm{V}$ peak is also clearly present. Taking a closer look at the pDOS between $-2 \mathrm{eV}$ and $\mathrm{EF}$, we recognize that for the $\mathrm{Fe}$ and the Mn-containing compounds there is essentially a full hybridization of oxygen $\mathrm{p}$ and TM d-states, meaning that no significant anionic redox is expected. In the case of Co, there are some excess oxygen p-states which may contribute to anionic redox.

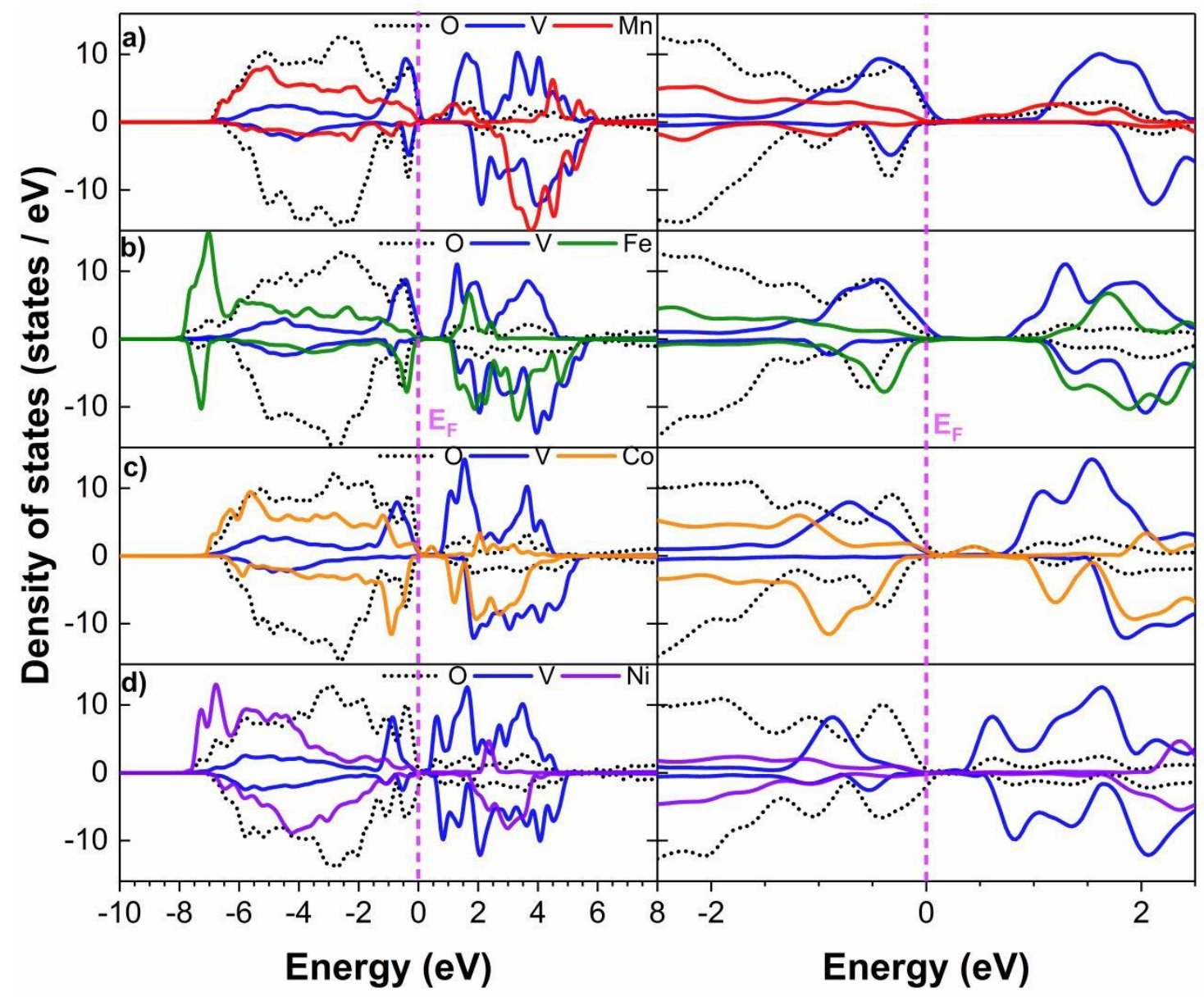

Figure 2: Partial density of states (oxygen p- and metal d-states) for a) $\mathrm{LiMn}_{0.5} \mathrm{~V}_{0.5} \mathrm{O}_{2}$ b) $\mathrm{LiFe}_{0.5} \mathrm{~V}_{0.5} \mathrm{O}_{2} \mathrm{c}$ ) LiCo0.5 $\mathrm{V}_{0.5} \mathrm{O}_{2}$ d) $\mathrm{LiNi}_{0.5} \underset{0.52}{\mathrm{O}} \mathrm{O}_{2}^{*}$ obtained from DFT. * Reproduced with permission. ${ }^{31}$ Copyright (2011) American Chemical Society. 


\section{Electrochemical Properties}

Stacked charge-discharge profiles of $\mathrm{LiM}_{0.5} \mathrm{~V}_{0.5} \mathrm{O}_{2}(\mathrm{M}=\mathrm{Mn}, \mathrm{Fe}, \mathrm{Co}, \mathrm{Ni})$ cycled between 4.5 $1.3 \mathrm{~V}$ at $20 \mathrm{~mA} \mathrm{~g}^{-1}$ with the corresponding differential capacity plots are shown in Figure 3. The previously studied LiNi0.5 $\mathrm{V}_{0.5} \mathrm{O}_{2}$ has been included for comparison. Theoretical capacities based on $1 \mathrm{e}^{-}$transfer are 292, 290, $286 \mathrm{mAh} \mathrm{g}^{-1}$ for $\mathrm{LiM}_{0.5} \mathrm{~V}_{0.5} \mathrm{O}_{2}(\mathrm{M}=\mathrm{Mn}, \mathrm{Fe}, \mathrm{Co})$, respectively. As expected from our DFT calculations, the average discharge voltages increase in the order of $\mathrm{Mn}<\mathrm{Fe}<\mathrm{Co}<\mathrm{Ni}$ with values of 2.28, 2.41, 2.51, 2.55 V, respectively. The differential capacity plots of $\mathrm{LiMn} 0.5 \mathrm{~V}_{0.5} \mathrm{O}_{2}$ and $\mathrm{LiFe} 0.5 \mathrm{~V}_{0.5} \mathrm{O}_{2}$ display broad peaks with the maxima centered at 2.0 and $2.4 \mathrm{~V}$ for the discharge and 2.6 and $2.8 \mathrm{~V}$ for the charge. In contrast, $\mathrm{LiCo} .5 \mathrm{~V}_{0.5} \mathrm{O}_{2}$ displays very broad peaks with no clear maxima during discharge, but two peaks were observed for the charge at 2.9 and $4.2 \mathrm{~V}$. These observations are also reflected in the charge-discharge profiles. $\mathrm{LiMn} 0.5 \mathrm{~V}_{0.5} \mathrm{O}_{2}$ and $\mathrm{LiFe} 0.5 \mathrm{~V}_{0.5} \mathrm{O}_{2}$ are showing a more plateaulike behavior, whereas $\mathrm{LiCo} .5 \mathrm{~V}_{0.5} \mathrm{O}_{2}$ shows a more sloping voltage profile. XANES measurement in our previous study revealed that 0.5 out of $0.94 \mathrm{Li}$, which could be extracted from $\mathrm{LiNi} 0.5 \mathrm{~V}_{0.5} \mathrm{O}_{2}$ correspond to $\mathrm{V}^{+4 /+5}$ redox. All presented compounds show lithium insertion/extraction capabilities beyond $0.5 \mathrm{Li}$ per formula unit, which implies both transition metals to be redox-active.

LiNi ${ }_{0.5} \mathrm{~V}_{0.5} \mathrm{O}_{2}$ is in sharp contrast to other compounds as it displays a characteristic voltage plateau at $4.2 \mathrm{~V}$ during charge, which has been ascribed to oxygen activity in the literature. ${ }^{40}$ This observation is supported by our DFT results showing a strong contribution of the oxygen p-states close to the Fermi level and lower hybridization with the d-states of the transition metal. $\mathrm{LiCo} 0.5 \mathrm{~V}_{0.5} \mathrm{O}_{2}$ showed a small redox contribution around $4.2 \mathrm{~V}$ during charge, as indicated by the differential capacity plot in Figure 3. This again is in agreement with the excess oxygen p-states observed in our DFT calculations. In $\mathrm{LiNi} 0.5 \mathrm{~V}_{0.5} \mathrm{O}_{2}$ cathode material, the higher voltage hysteresis of $\mathrm{Ni}^{3+/ 2+}$ systems has been associated with narrower bandgap and structural modification due to the Jahn-Teller distortion, which can trigger oxygen loss 
and cation migration leading to a higher voltage hysteresis. ${ }^{41}$ Similar to $\mathrm{LiNi} 0.5 \mathrm{~V}_{0.5} \mathrm{O}_{2}$ cathode, LiMn $0.5 \mathrm{~V}_{0.5} \mathrm{O}_{2}$ cathode also shows comparatively higher voltage hysteresis, which might be due to the Jahn-Teller (JT) distortion ( $\mathrm{d}^{4}$ and $\mathrm{d}^{7}$ electron configuration) upon oxidation. ${ }^{42,43}$

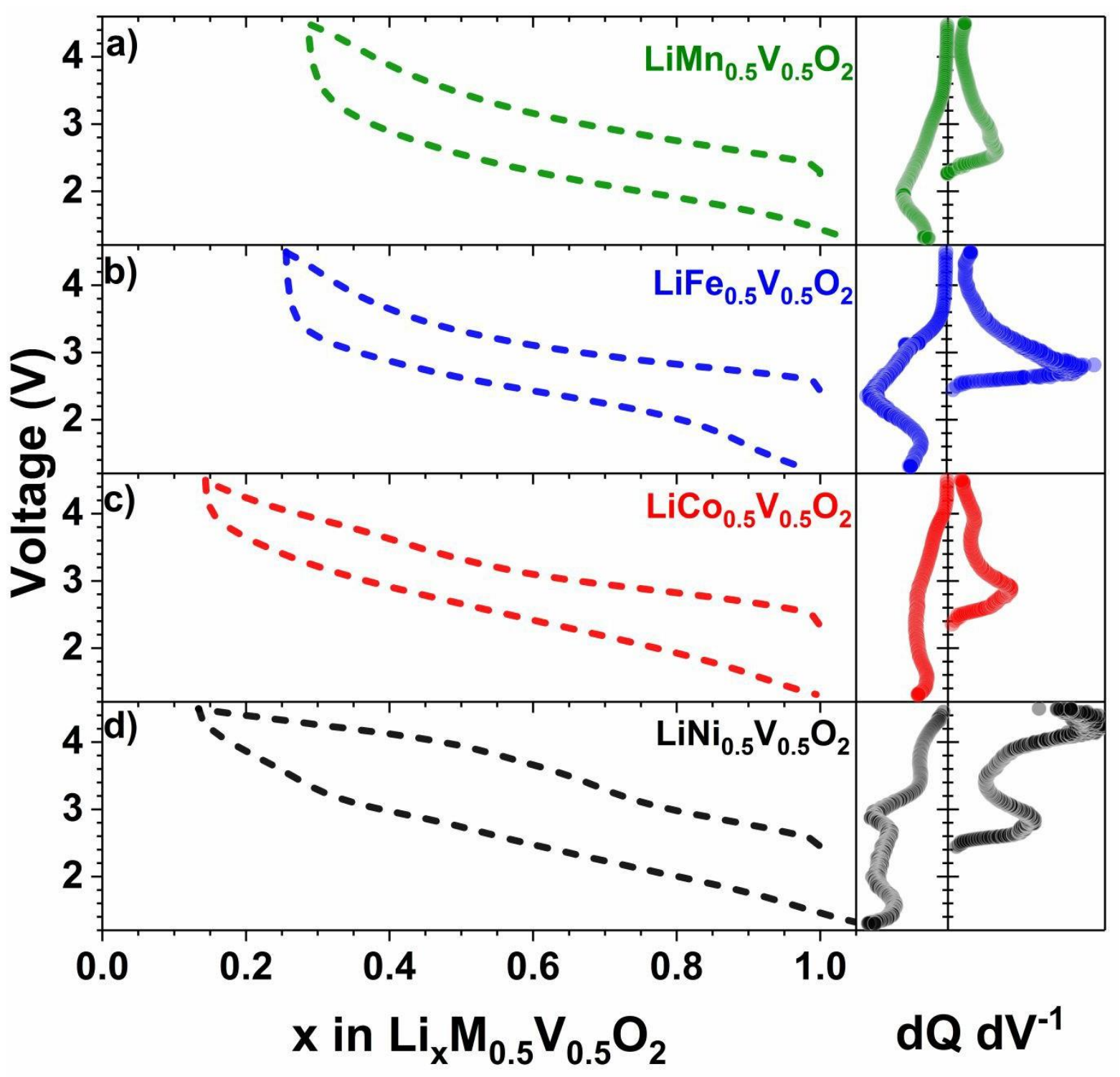

Figure 3: Charge-discharge voltage profile with respective differential capacity plot during the first cycle for a) $\mathrm{LiMn}_{0.5} \mathrm{~V}_{0.5} \mathrm{O}_{2}$ b) $\mathrm{LiFe}_{0.5} \mathrm{~V}_{0.5} \mathrm{O}_{2}$ and c) $\mathrm{LiCo}_{.5} \mathrm{~V}_{0.5} \mathrm{O}_{2}$ d) $\mathrm{LiNi} \mathrm{V}_{0.5}{ }_{0.5} \mathrm{O}_{2}^{*}$ ** Adapted with permission. ${ }^{31}$ Copyright (2011) American Chemical Society. 


\section{$\mathrm{LiM}_{0.5} \mathrm{~V}_{0.5} \mathrm{O}_{2}(\mathrm{M}=\mathrm{Mn}, \mathrm{Co})$ with disordered rock-salt structure}

In the remaining sections, we mainly discuss the electrochemical results of $\mathrm{LiMn}_{0.5} \mathrm{~V}_{0.5} \mathrm{O}_{2}$ and LiCo0.5 $\mathrm{V}_{0.5} \mathrm{O}_{2}$ compounds only. $\mathrm{LiFe}_{0.5} \mathrm{~V}_{0.5} \mathrm{O}_{2}$ will not be further discussed at this point. The influence of the specific current and the cycling window on the cycling stability, specific capacity, and voltage hysteresis was examined. Figure 4a,b shows the cycling stability and discharge capacity of $\mathrm{LiMn} 0.5 \mathrm{~V}_{0.5} \mathrm{O}_{2}$ and $\mathrm{LiCo} .5 \mathrm{~V}_{0.5} \mathrm{O}_{2}$ cycled between $4.5-1.3 \mathrm{~V}$ at different specific currents. Similarly, both compounds show strong capacity decay upon cycling. Note that $\mathrm{LiCo} .5 \mathrm{~V}_{0.5} \mathrm{O}_{2}$ exhibits higher specific discharge capacities compared to $\mathrm{LiMn} 0.5 \mathrm{~V}_{0.5} \mathrm{O}_{2}$, but also shows extensive capacity fading. The cycling stability appears to depend on the applied specific current. For faster cycling with higher specific current, the capacity retention increases significantly. After 75 cycles the capacity retention was $37 \%$ exhibiting a specific capacity of $85 \mathrm{mAh} \mathrm{g}^{-1}$ at $20 \mathrm{~mA} \mathrm{~g}^{-1}$ and $56 \%$ with $115 \mathrm{mAh} \mathrm{g}^{-1}$ at $200 \mathrm{~mA} \mathrm{~g}^{-1}$ for

LiCo0.5 $\mathrm{V}_{0.5} \mathrm{O}_{2}$. Similar observations were made for $\mathrm{LiMn} 0.5 \mathrm{~V}_{0.5} \mathrm{O}_{2}$, which showed capacity retention of $39 \%$ with $79 \mathrm{mAh} \mathrm{g}^{-1}$ and $57 \%$ with $73 \mathrm{mAh} \mathrm{g}^{-1}$, respectively. Figure $4 \mathbf{c}$,d shows the rate performance for both compounds, which involved three consecutive cycles at a specific current. For the applied specific currents of 20,50, 100, 200, $400 \mathrm{~mA} \mathrm{~g}^{-1}$, LiMn $0.5 \mathrm{~V}_{0.5} \mathrm{O}_{2}$ exhibited a specific capacity of $219,161,128,93,53 \mathrm{mAh} \mathrm{g}^{-1}$, respectively and LiCo $.5 \mathrm{~V}_{0.5} \mathrm{O}_{2}$ exhibited 234, 192, 154, 116, $78 \mathrm{mAh} \mathrm{g}^{-1}$, respectively .The corresponding first charge-discharge profile of each current step is illustrated in Figure 4e,f for LiMn V O

and $\mathrm{LiCo} 0.5 \mathrm{~V}_{0.5} \mathrm{O}_{2}$, respectively. 


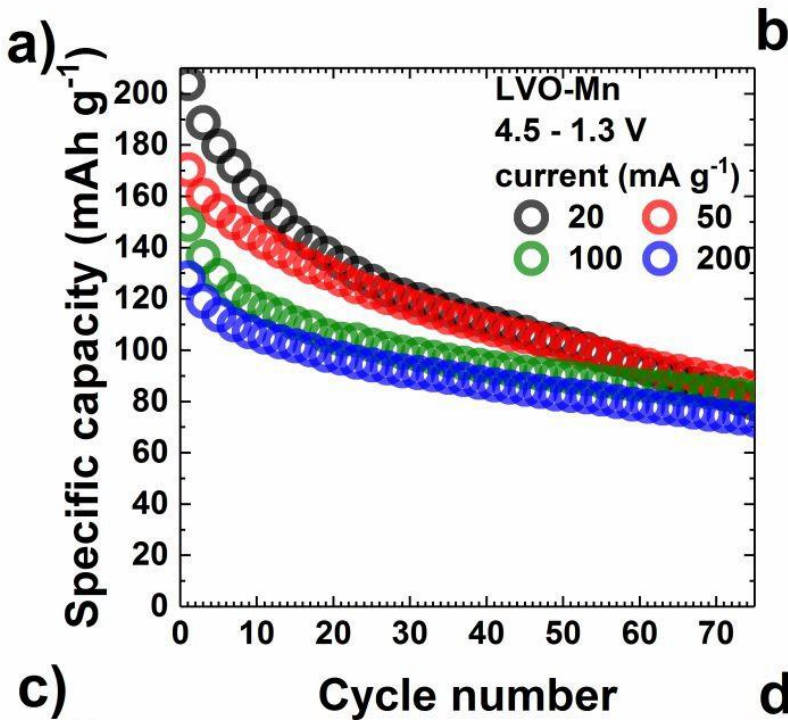

c)
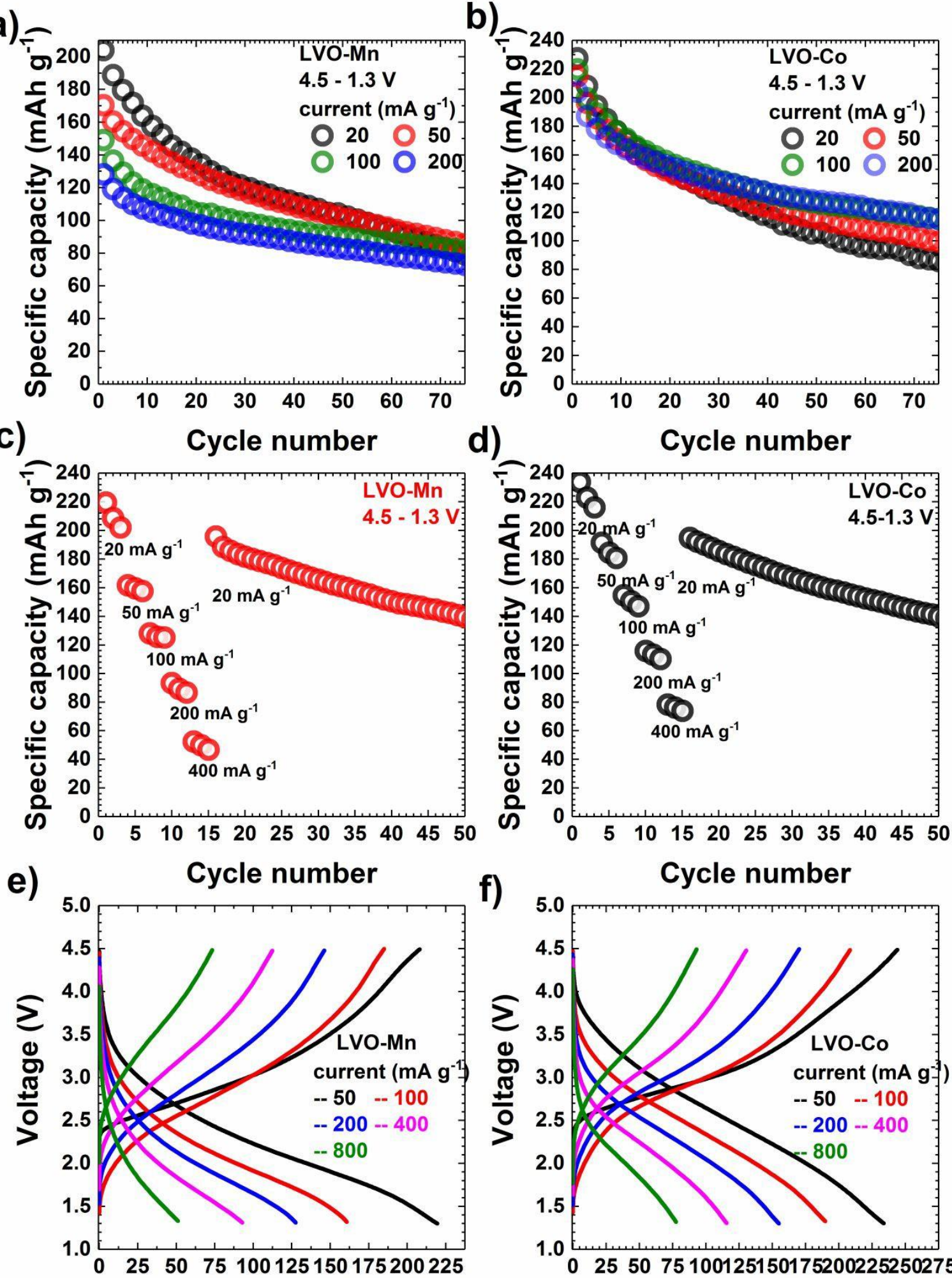

f)

Cycle number

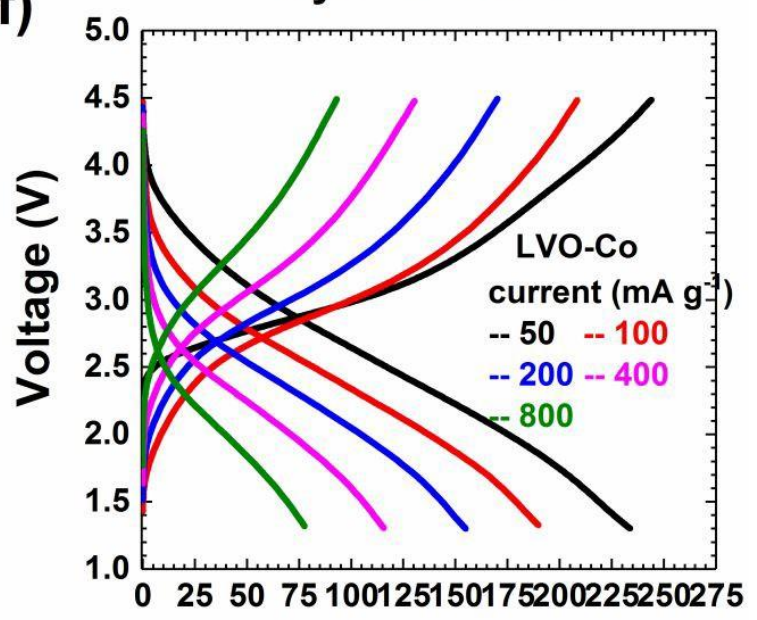

Specific capacity $\left(\mathrm{mAh} \mathrm{g}^{-1}\right)$

\section{Specific capacity ( $\mathrm{mAh} \mathrm{g}^{-1}$ )}

Figure 4: Cycling stability in the voltage window between 4.5-1.3 V for different currents for a) $\mathrm{LiMn} 0.5 \mathrm{~V}_{0.5} \mathrm{O}_{2}$ and b) $\mathrm{LiCo} 0.5 \mathrm{~V}_{0.5} \mathrm{O}_{2}$. Rate capability test with 3 consecutive cycles at a given current in the range of 4.5-1.3 $\mathrm{V}$ for c) $\mathrm{LiMn}_{0.5} \mathrm{~V}_{0.5} \mathrm{O}_{2}$ and d) $\mathrm{LiCo}_{0.5} \mathrm{~V}_{0.5} \mathrm{O}_{2}$. First cycle voltage profile for each current of the rate capability test for e) $\mathrm{LiMn}_{0.5} \mathrm{~V}_{0.5} \mathrm{O}_{2}$ and f) $\mathrm{LiCo}_{0.5} \mathrm{~V}_{0.5} \mathrm{O}_{2}$. 
The influence of the cut-off voltage on the cycling stability and the voltage hysteresis have been examined for a constant current measurement with $50 \mathrm{~mA} \mathrm{~g}^{-1}$. The cycling stability is shown in Figure 5a,b and the respective charge-discharge profiles for $\mathrm{LiMn}_{0.5} \mathrm{~V}_{0.5} \mathrm{O}_{2}$ and LiCo0.5 $\mathrm{V}_{0.5} \mathrm{O}_{2}$ are depicted in Figure 5c,d. When cycling is limited between $2.0 \leq \mathrm{x} \leq 4.0 \mathrm{~V}$, the cycling stability increases significantly in both cases. Capacity fading is more severe for a wide cycling window between 4.5-1.3 V. A comparably narrow cycling window, on the other hand, results in a reduced specific capacity. For cycling in the voltage window between 4.02.0 $\mathrm{V}$ the cells exhibited a specific capacity of $152 \mathrm{mAh} \mathrm{g}^{-1}$ and $100 \mathrm{mAh} \mathrm{g}^{-1}$, whereas the wide cycling window exhibited a specific capacity of $210 \mathrm{mAh} \mathrm{g}^{-1}$ and $171 \mathrm{mAh} \mathrm{g}^{-1}$ for LiCo0.5 $\mathrm{V}_{0.5} \mathrm{O}_{2}$ and $\mathrm{LiMn} 0.5 \mathrm{~V}_{0.5} \mathrm{O}_{2}$, respectively. A striking fact is that hysteresis is lower for LiCo0.5 $\mathrm{V}_{0.5} \mathrm{O}_{2}$ when compared to LiMn0.5 $\mathrm{V}_{0.5} \mathrm{O}_{2}$. For a wider cycling window with $2.0 \geq \mathrm{x}$ $\geq 4.0 \mathrm{~V}$, with deeper discharge and/or higher charge cut-off, an apparent increase in voltage hysteresis can be observed for both compounds towards the end of discharge/charge. This suggests possibly slower kinetics due to bulk diffusion limitations in this region. ${ }^{44}$ 
a)

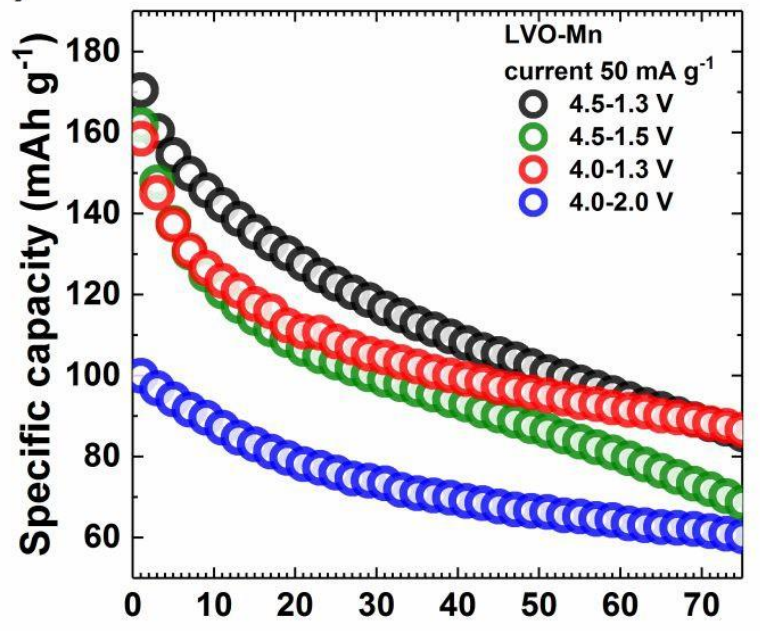

C)

c)

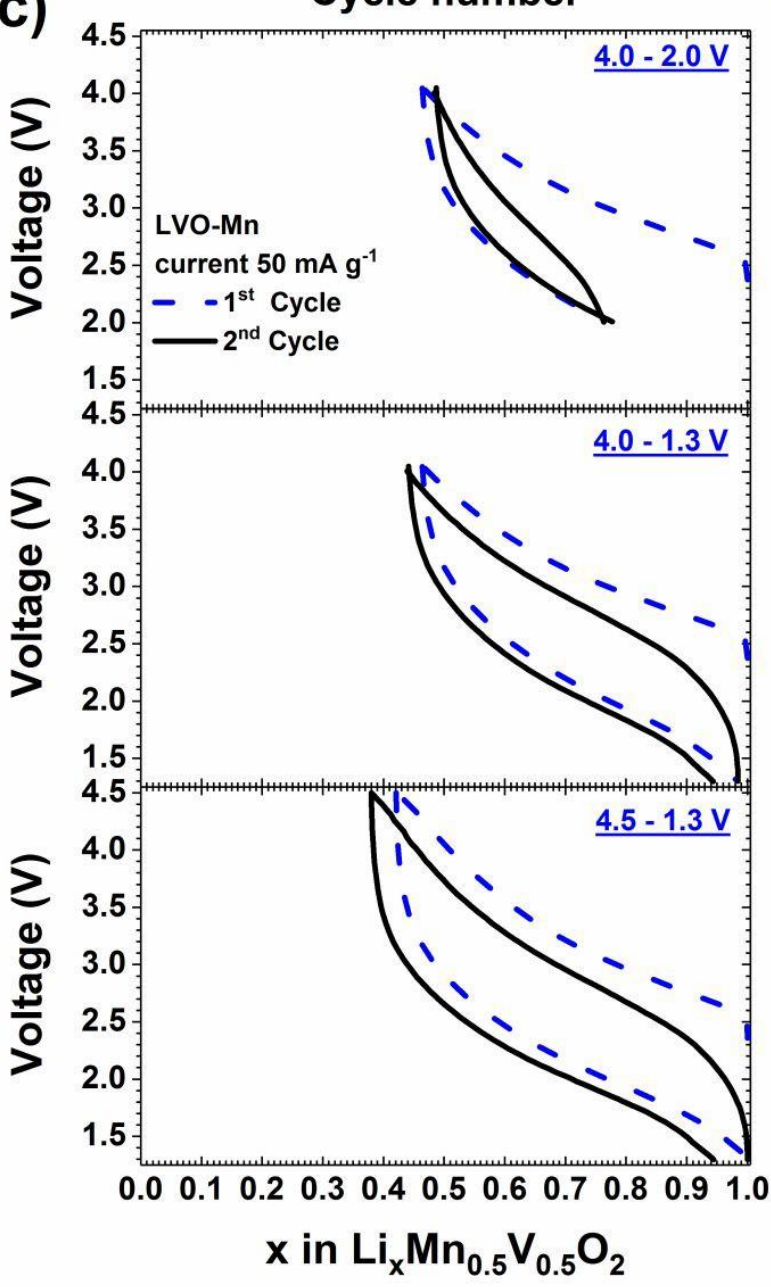

b)

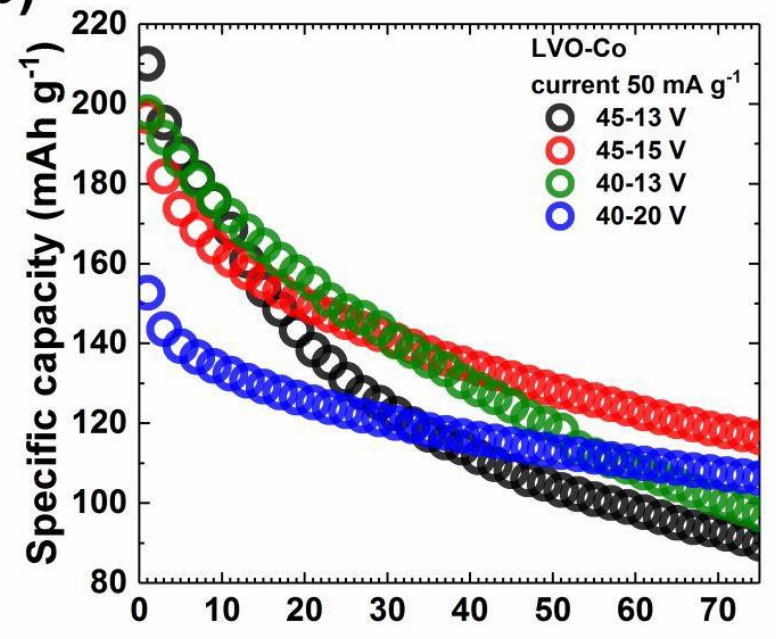

d) Cycle number

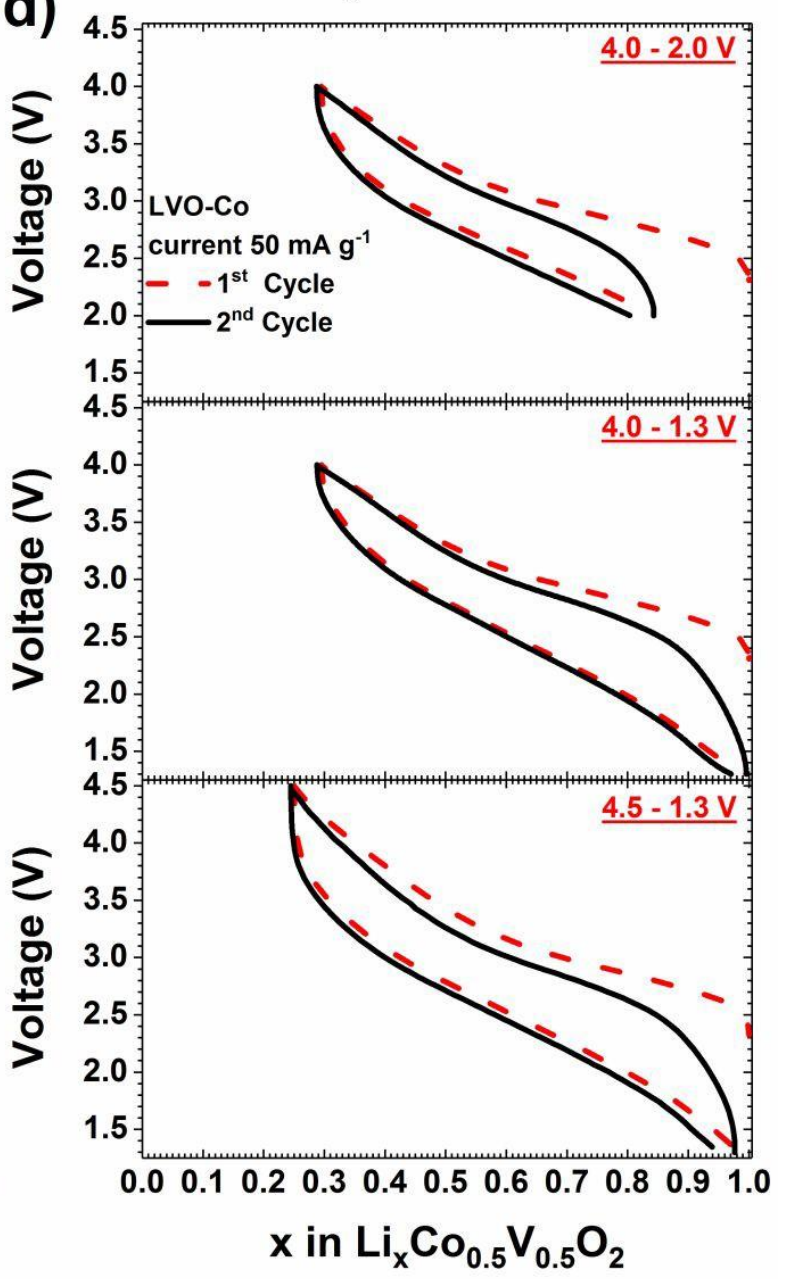

Figure 5: Cycling stability for various cut-off voltages at $50 \mathrm{~mA} \mathrm{~g}^{-1}$ for a) $\mathrm{LiMn}_{0.5} \mathrm{~V}_{0.5} \mathrm{O}_{2}$ and b) $\mathrm{LiCo} 0.5 \mathrm{~V}_{0.5} \mathrm{O}_{2}$. Respective first cycle charge-discharge voltage profile with various cut-off voltages for c) $\mathrm{LiMn} 0.5 \mathrm{~V}_{0.5} \mathrm{O}_{2}$ and d) $\mathrm{LiCo} .5 \mathrm{~V}_{0.5} \mathrm{O}_{2}$. 


\section{Conductivity study}

The charge-discharge profiles show a large voltage hysteresis with larger polarization overpotentials implying kinetic limitations. In fact, the electrode kinetic is determined by electronic and ionic conductivity, which both can limit the rate performance. ${ }^{45}$ At first, the electronic conductivity and in the later part, the apparent lithium diffusion coefficient were determined. The electronic conductivity of $\mathrm{LiCo} 0.5 \mathrm{~V}_{0.5} \mathrm{O}_{2}$ and $\mathrm{LiMn} 0.5 \mathrm{~V}_{0.5} \mathrm{O}_{2}$ has been measured by alternating current (AC) impedance spectroscopy at various temperatures (25$\left.80{ }^{\circ} \mathrm{C}\right)$. The impedance data and the corresponding equivalent electrical circuits that describes the impedance behavior of the electrodes are depicted in Figure 6a, b. Constant phase elements (CPEs) and resistors are denoted by the symbols ' $Q$ ' and ' $R$ ' in the equivalent circuits. The capacitance $(C)$ can be described as a function of ' $Q$ ' and ' $n$ ' and is obtained by fitting the relation $C=\left(R^{1-n} Q\right)^{1 / n}$, where ' $n$ ' is essentially a measure for the degree of depression of an arc. The fitting of the equivalent electrical circuit yields capacitance values of $\sim 10^{-10} \mathrm{~F}$ for both samples, thus confirming that the observed impedance responses originate mainly from the bulk (grains) of the samples. The lack of any additional polarization process at low frequencies shows that the conduction in these samples is mainly due to electronic carriers, and this observation is again confirmed by DC polarization studies. The activation energy ( $\mathrm{Ea}_{a}$ for $\mathrm{LiCo} 0.5 \mathrm{~V}_{0.5} \mathrm{O}_{2}$ and $\mathrm{LiMn} 0.5 \mathrm{~V}_{0.5} \mathrm{O}_{2}$ was determined using the Arrhenius equation evaluating the slope of $\log (\sigma) v s . T^{-1}$, as shown in Figure 6c, d. Here ' $\sigma$ ' is the total conductivity, and ' $T$ ' is the absolute temperature. Both $\operatorname{LiCo} 0.5 \mathrm{~V}_{0.5} \mathrm{O}_{2}$ and $\mathrm{LiMn}_{0.5} \mathrm{~V}_{0.5} \mathrm{O}_{2}$ showed a comparable room temperature conductivity of $\sim 4.1 \times 10^{-6} \mathrm{~S} \mathrm{~cm}^{-1}$ as and $\sim 3.5 \times 10^{-6} \mathrm{~S} \mathrm{~cm}^{-1}$, respectively. The activation energy of $\mathrm{LiCo} 0.5 \mathrm{~V}_{0.5} \mathrm{O}_{2}$ was determined to be 224( \pm 13$) \mathrm{meV}$, while for $\mathrm{LiMn}_{0.5} \mathrm{~V}_{0.5} \mathrm{O}_{2}$ a value of $252( \pm 6) \mathrm{meV}$. Even though the pristine samples show reasonably high electronic conductivity, it is noteworthy that, with respect to the state of charge and cycling, the conductivity is expected to change. 

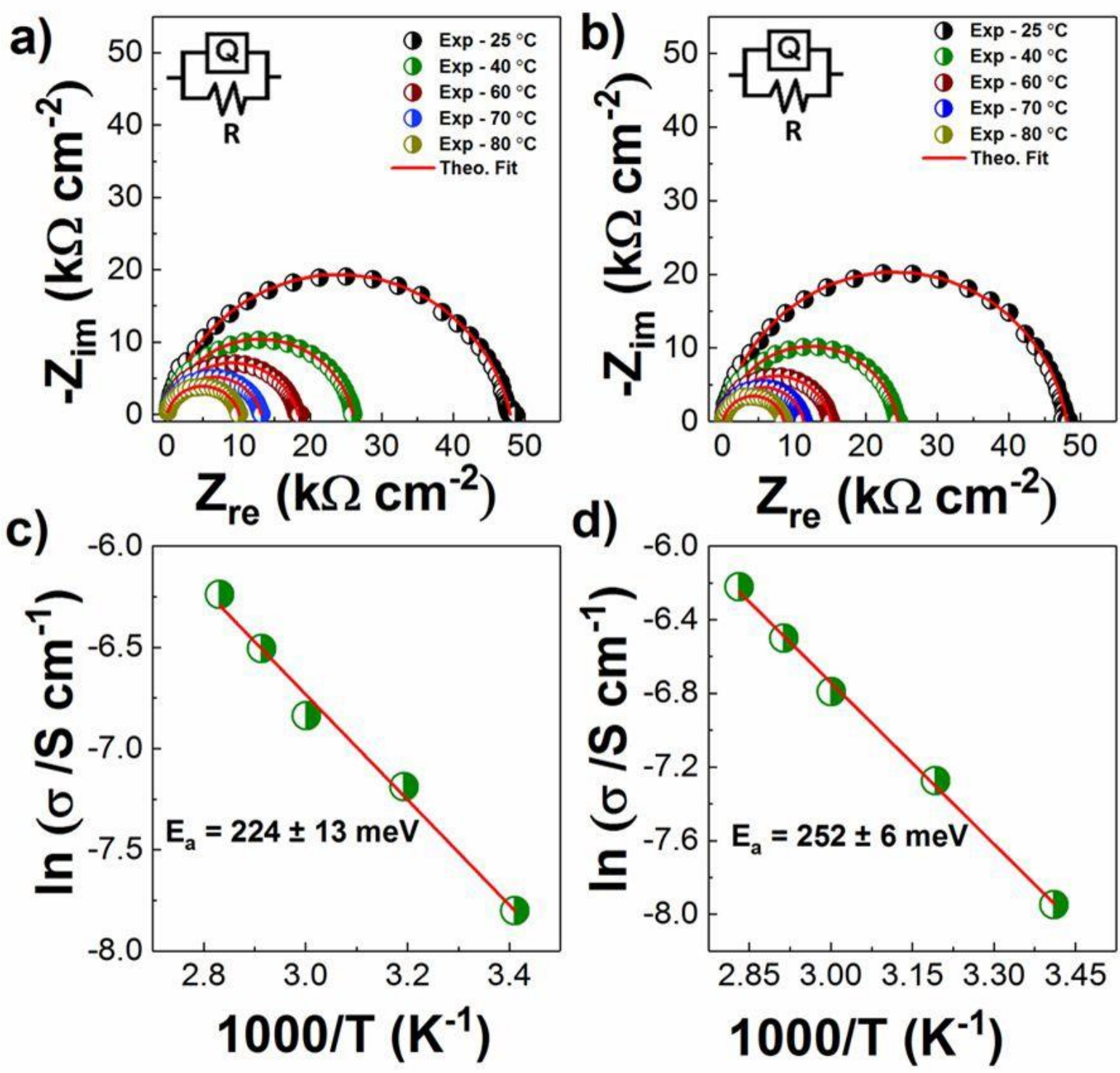

Figure 6: Nyquist plots of the impedances at different temperatures $\left(25-80{ }^{\circ} \mathrm{C}\right)$ for

a) $\mathrm{LiCo} 0.5 \mathrm{~V}_{0.5} \mathrm{O}_{2}$ and b) $\mathrm{LiMn} 0.5 \mathrm{~V}_{0.5} \mathrm{O}_{2}$. Arrhenius plots of the activation energy for

c) $\mathrm{LiCo} 0.5 \mathrm{~V}_{0.5} \mathrm{O}_{2}$ and d) LNO-Mn.

The apparent lithium diffusion coefficients for $\mathrm{LiCo} 0.5 \mathrm{~V}_{0.5} \mathrm{O}_{2}$ and $\mathrm{LiMn} 0.5 \mathrm{~V}_{0.5} \mathrm{O}_{2}$ have been determined by cyclic voltammetry (CV) experiments using the Randles-Sevcik equation. ${ }^{46}$ The CV at various scan rates from 0.05 to $0.5 \mathrm{mV} \mathrm{s}^{-1}$ curves of both $\mathrm{LiCo0.5} \mathrm{V}_{0.5} \mathrm{O}_{2}$ and LiMn $_{0.5} \mathrm{~V}_{0.5} \mathrm{O}_{2}$ (Figure $7 \mathbf{a , b}$ ) illustrate an increase in the peak current and a separation in the oxidation/reduction peaks with respect to the increasing scan rates. Oxidation/reduction peak currents ( $\mathrm{I}_{\mathrm{p}}$ ) of $\mathrm{LiCo} .5 \mathrm{~V}_{0.5} \mathrm{O}_{2}$ and $\mathrm{LiMn}_{0.5} \mathrm{~V}_{0.5} \mathrm{O}_{2}$ are proportional to the square root of the scan 
rate (v) as shown in Figure 7a,b and Figure S8 (supporting information), which shows a semi-infinite linear diffusion behavior, indicating that the current for this range is controlled by bulk diffusion processes rather than surface contributions. ${ }^{47}$ The apparent lithium-ion diffusion coefficients for $\mathrm{LiMn}_{0.5} \mathrm{~V}_{0.5} \mathrm{O}_{2}$ and $\mathrm{LiCo} 0.5 \mathrm{~V}_{0.5} \mathrm{O}_{2}$ obtained from $\mathrm{CV}$ is $\sim 2.7 \times 10^{-16}$ $\mathrm{cm}^{2} \mathrm{~s}^{-1}$ and $1.2 \times 10^{-15} \mathrm{~cm}^{2} \mathrm{~s}^{-1}$, respectively.
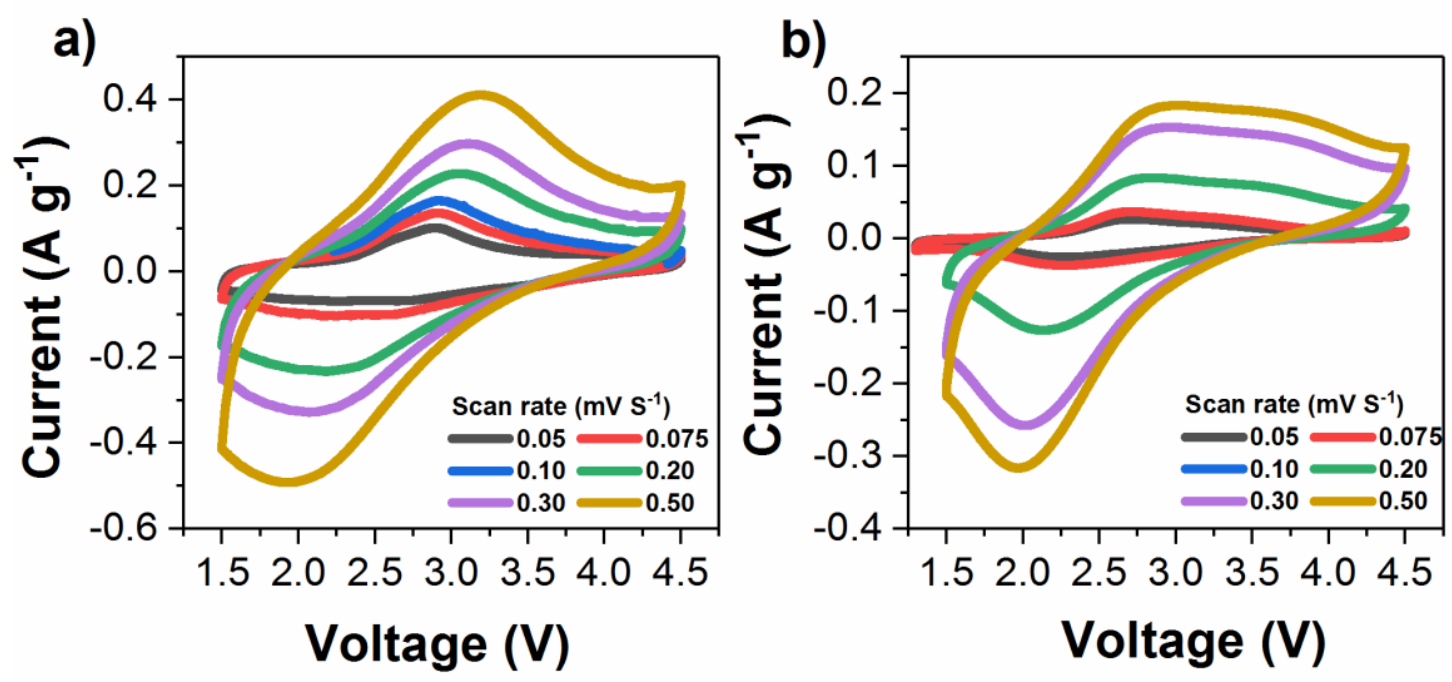

Figure 7: Cyclic voltammograms for a) $\mathrm{LiCo} 0.5 \mathrm{~V}_{0.5} \mathrm{O}_{2}$ and b) $\mathrm{LiMn}_{0.5} \mathrm{~V}_{0.5} \mathrm{O}_{2}$ at various voltage scan rates.

\section{Reaction mechanism}

Structural changes of the positive electrode materials were studied by XRPD measurements of LiMn $0.5 \mathrm{~V}_{0.5} \mathrm{O}_{2}$ and $\mathrm{LiCo} 0.5 \mathrm{~V}_{0.5} \mathrm{O}_{2}$ were carried out for different states of charge. The XRPD data with the corresponding Rietveld refinement fit for the charged state (at $4.5 \mathrm{~V}$ ) and discharged state (at $1.5 \mathrm{~V}$ ) after charging to $4.5 \mathrm{~V}$ are shown in Figure 8a-d. The corresponding lattice constants are shown in Table S1. After charging, the lattice constant decreased due to the lattice contraction resulting from Li removal. This can also be associated with the $\mathrm{V}^{+4 /+5}\left[\mathrm{~V}^{+4}(\mathrm{r}=0.58 \AA) \text { and } \mathrm{V}^{+5}(\mathrm{r}=0.46 \AA)\right]^{48}$ redox reaction, which has been shown to be the dominant redox process for $\mathrm{LiNi}_{0.5} \mathrm{~V}_{0.5} \mathrm{O}_{2}$. Furthermore, the $\mathrm{Mn}^{+2 /+3}$ redox 
couple [with $\mathrm{Mn}^{+2}(\mathrm{r}=0.69 \AA)$ and $\left.\mathrm{Mn}^{+3}(\mathrm{r}=0.56 \AA)\right]^{48}$ for $\mathrm{LiMn}_{0.5} \mathrm{~V}_{0.5} \mathrm{O}_{2}$ and $\mathrm{Co}^{+2 /+3}$ redox couple [with $\mathrm{Co}^{+2}(\mathrm{r}=0.65 \AA)$ and $\left.\mathrm{Co}^{+3}(\mathrm{r}=0.61 \AA)\right]^{48}$ for $\mathrm{LiCo}_{0.5} \mathrm{~V}_{0.5} \mathrm{O}_{2}$ can contribute to the charge compensation and volume decrease as also suggested by our DFT results. In general, the changes in the lattice parameter are small. The cubic structure is preserved and can be indexed accordingly. However, the diffraction pattern of the charged materials show a large change in the intensity distribution of the prominent Bragg reflections of the cubic rock salt type structure, i.e., the intensity of the 111 reflections strongly decreases, and the intensity ratio $\mathrm{I}_{22} / \mathrm{I}_{200}$ deviates from the pristine state. We conclude that, due to transition metal migration from octahedral to tetrahedral sites (4a to 8c Wyckoff position), a certain structural rearrangement takes place upon delithiation. From the Rietveld refinement, this site migration can be estimated to be in the order of approximately $5 \%$. However, in order to unambiguously prove this mechanism, neutron diffraction studies would be required. It is interesting to note that after the first charge, intensity loss with an increase in the background was observed, without complete recovery after discharge. Similar observations have been made for other disordered rock-salt oxides, which have been associated with the partially reversible structural reorganization. ${ }^{49,50}$ 
a)

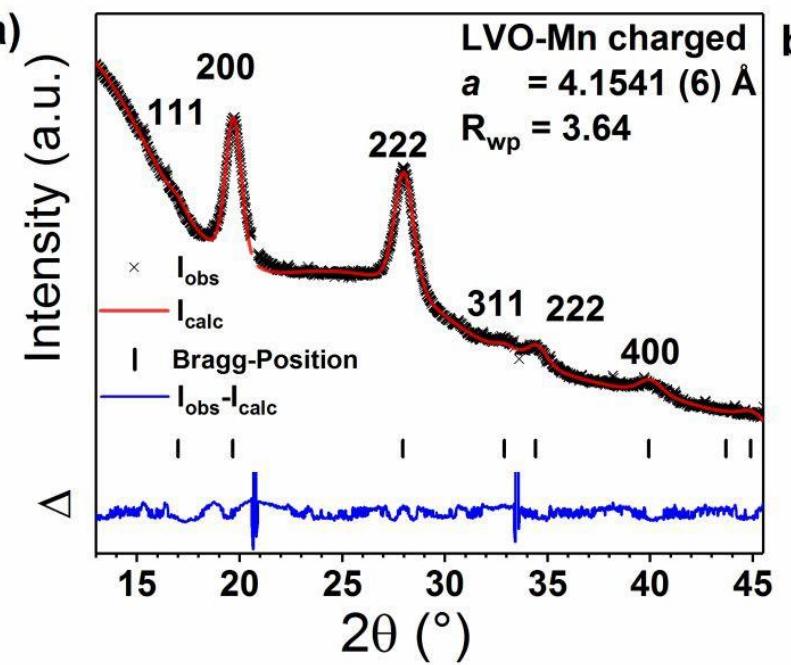

c)

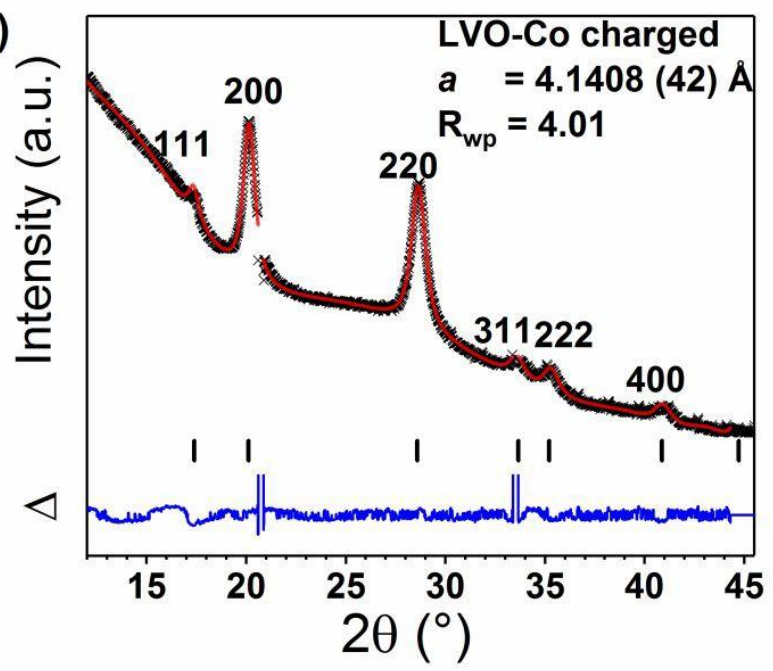

b)

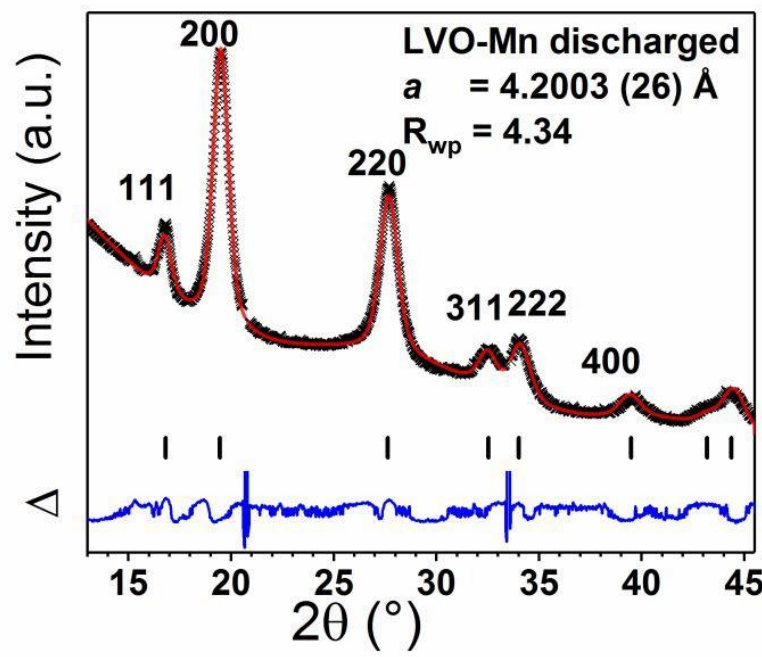

d)

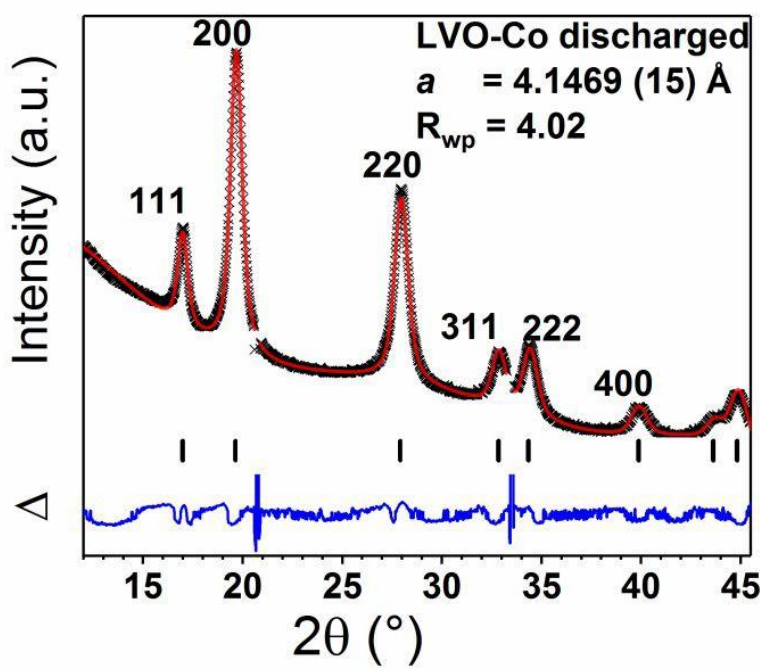

Figure 8: Ex-Situ XRPD for different states of charge with charging to $4.5 \mathrm{~V}$ and subsequently discharging to $1.5 \mathrm{~V}$ for a) $\mathrm{LiMn} 0.5 \mathrm{~V}_{0.5} \mathrm{O}_{2}$ charged b) $\mathrm{LiMn} 0.5 \mathrm{~V}_{0.5} \mathrm{O}_{2}$ discharged c) LiCo $\mathrm{V} \quad \underset{0}{\mathrm{O}}$ charged d) LiCo $\underset{0.5}{\mathrm{~V}} \quad 0_{0.52}^{\mathrm{O}}$ discharged. The gaps in the diffraction pattern are due to the gaps in the Pilatus $300 \mathrm{~K}-\mathrm{W}$ detector.

\section{Metal dissolution}

Capacity fading may originate partly due to electrolyte side reactions ${ }^{51}$ or charged state instabilities of the material. ${ }^{52}$ Therefore, to track down eventual metal dissolution extensively cycled electrodes have been disassembled, and elemental maps were collected from the lithium metal surface as shown in Figure S5, S6. The elemental maps reveal transition metal deposition on the lithium anode. $\mathrm{LiMn}_{0.5} \mathrm{~V}_{0.5} \mathrm{O}_{2}$ and $\mathrm{LiCo} 0.5 \mathrm{~V}_{0.5} \mathrm{O}_{2}$ for the pristine and 
chemically delithiated state were immersed in electrolyte for 7 days at $45^{\circ} \mathrm{C}$ to and quantified by inductively coupled plasma optical emission spectroscopy (ICP-OES) as shown in Table 1. From Table 1 and the calculated dissolution ratios, it is evident that the dissolution is significantly increased in the charged state. For high delithiation degrees, significant dissolution of the different TMs was observed. Similar observations have previously been made for other vanadium-based cathode materials, which have been synthesized in a similar way and for which vanadium dissolution has also been evidenced. ${ }^{13,31,53}$. The capacity fading in both compounds, resulting from the loss of active material, is significantly smaller than the overall capacity fading. This finding suggests that the capacity fading is not only influenced by the active material loss. We, therefore, argue that additional electrolyte side reactions could be responsible for capacity fading.

Table 1: Fraction of the transition metal dissolving in the electrolyte at elevated temperatures $\left(\mathrm{T}=45^{\circ} \mathrm{C}\right)$ for pristine and charged state

\begin{tabular}{|c|c|c|c|c|}
\hline \multirow{2}{*}{ Compound } & \multirow{2}{*}{ Element } & Charged state & Pristine state & \multirow{2}{*}{ Ratio } \\
\cline { 3 - 5 } & & $4939 \pm 54$ & $261 \pm 8$ & 18.9 \\
\hline \multirow{2}{*}{$\mathbf{L i M n}_{\mathbf{0 . 5}} \mathbf{V}_{\mathbf{0 . 5}} \mathbf{O}_{\mathbf{2}}$} & $\mathrm{V}$ & $5041 \pm 56$ & $242 \pm 7$ & 20.8 \\
\cline { 3 - 5 } & $\mathrm{Mn}$ & $3612 \pm 40$ & $205 \pm 6$ & 17.6 \\
\hline $\mathbf{L i C o}_{\mathbf{0 . 5}} \mathbf{V}_{\mathbf{0 . 5}} \mathbf{O}_{\mathbf{2}}$ & $\mathrm{V}$ & $5942 \pm 66$ & $537 \pm 16$ & 11.1 \\
& $\mathrm{Co}$ & & & \\
\cline { 3 - 6 } & & & & \\
\end{tabular}

\section{Impact of the electrolyte salt on the cycling stability}

The presented compounds show low cycling stability, which can only partly be ascribed to transition metal migration and dissolution, as indicated above. A further critical element affecting cycling behavior is the electrolyte. The interactions between components of the 
electrolyte and the positive or and negative electrode can lead to significant side reactions, which in turn lead to capacity fading. The use of additives ${ }^{54,55}$ and/or changes in the electrolyte formulation by replacing the lithium salts have been shown to be useful measures to alleviate the capacity fading.

In order to study the influence on the cycling performance, we compared two electrolytes with different lithium salts. We tested the reported ${ }^{30} 5.5 \mathrm{M}$ lithium bis(fluorosulfonyl) imide (LiFSI) in dimethyl carbonate as an electrolyte to improve the cycling stability of the cathode materials and compared it to a conventional 1.0 M LiPF6 in ethylene carbonate dimethyl carbonate $(1: 1 \mathrm{w} / \mathrm{w})$ electrolyte. The influence of the different electrolytes on the cycling stability has been studied at a specific current of $200 \mathrm{~mA} \mathrm{~g}^{-1}$ in the cycling window between 4.5-1.3 V, as shown in Figure 9. The cells cycled with LiPF6 electrolyte for 100 cycles exhibit a capacity of $108 \mathrm{mAh} \mathrm{g}^{-1}$ for $\mathrm{LiCo} 0.5 \mathrm{~V}_{0.5} \mathrm{O}_{2}$, corresponding to $53 \%$ of the initial capacity and $65 \mathrm{mAh} \mathrm{g}^{-1}$ for $\mathrm{LiMn}_{0.5} \mathrm{~V}_{0.5} \mathrm{O}_{2}$ which amounts to $51 \%$ of the initial value.

However, the LiFSI containing electrolyte was found to increase cycling stability considerably. After 100 cycles, the cells exhibited a specific discharge capacity of $140 \mathrm{mAh} \mathrm{\textrm {g } ^ { - }}$ ${ }^{1}$ and $98 \mathrm{mAh} \mathrm{g}^{-1}$ corresponding to $68 \%$ and $72 \%$ of the initial capacity for $\mathrm{LiCo}_{0.5} \mathrm{~V}_{0.5} \mathrm{O}_{2}$ and LiMn $0.5 \mathrm{~V}_{0.5} \mathrm{O}_{2}$. The reasons why LiFSI electrolyte salt improves cycling performance are not yet clear. ${ }^{56}$ An advantage of excluding $\mathrm{LiPF}_{6}$ is to minimize the electrode degradation, caused by the formation of $\mathrm{HF}$, which has been found to enhance metal dissolution. The higher stability of LiFSI towards hydrolysis as compared to $\mathrm{LiPF}_{6}$ (organic carbonate solvents) in conjunction with lower interfacial resistances, were regarded as the cause for the higher cycling stability. ${ }^{57}$ Highly concentrated electrolytes bring some interesting benefits like lower solubility of other species such as transition metals, which possibly can be attributed to lower proportion or/and absence of free solvent molecules for the coordination of cations. Other advantages are the widened electrochemical stability and the mitigation of lithium dendrite 
growth. The disadvantage are the observed higher viscosity, electrode wetting issues, and the higher cost. ${ }^{58}$

a)

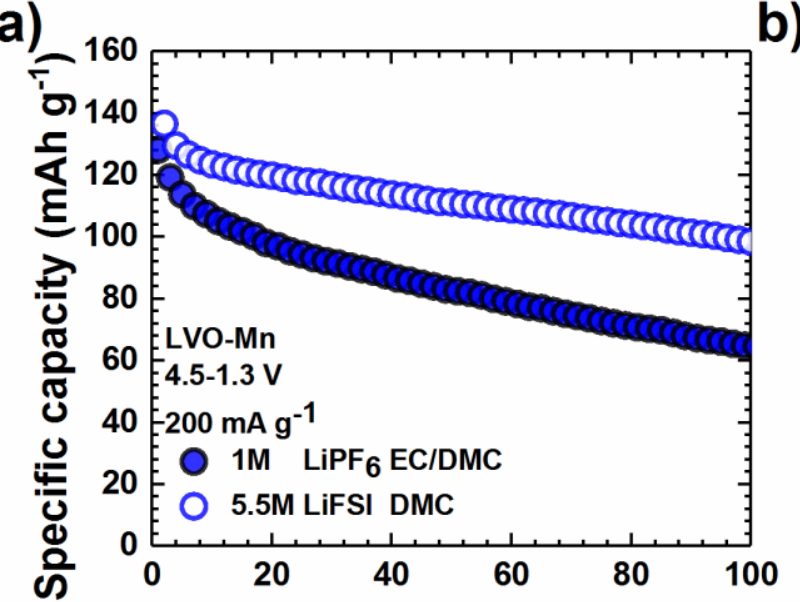

b)

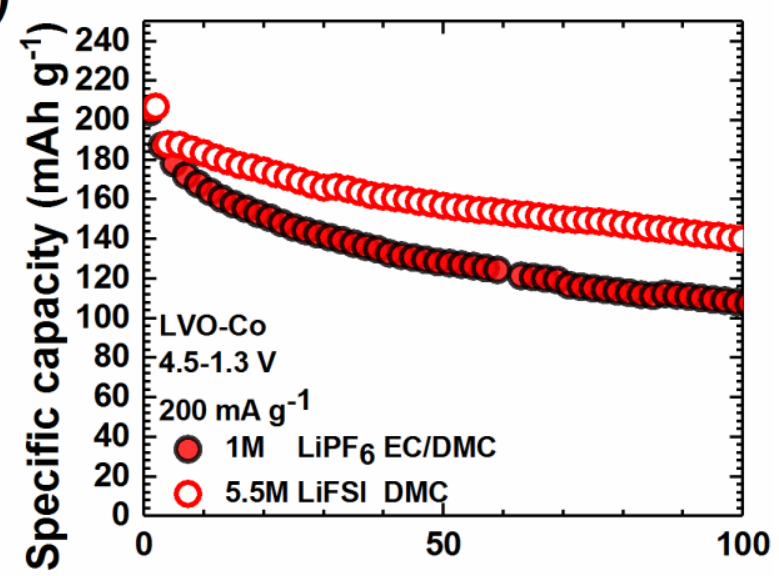

c)

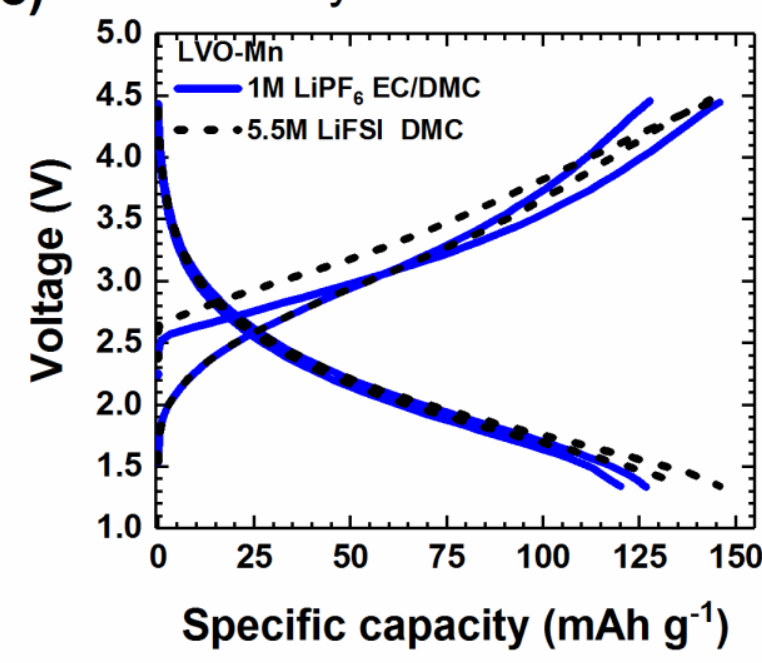

d)

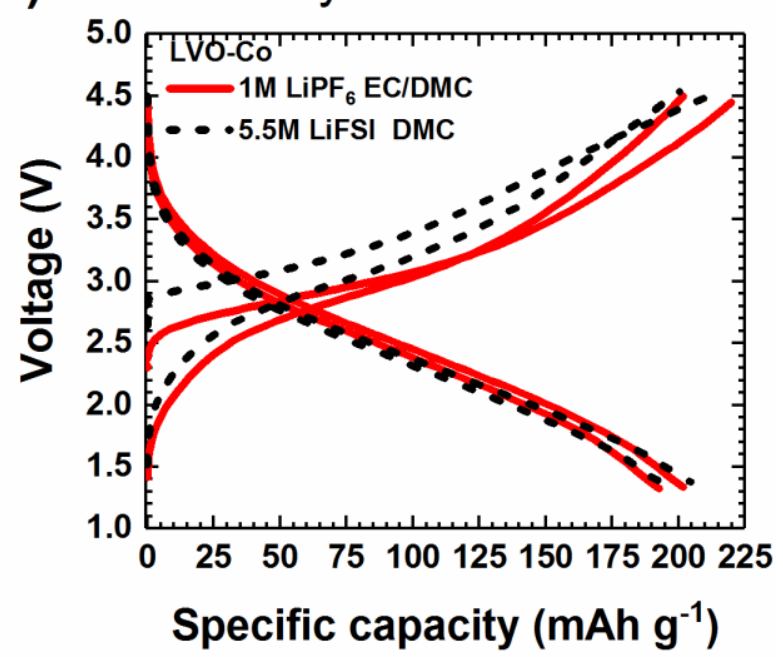

Figure 9: Cycling stability with two different electrolytes in the voltage window of 4.5-1.3 V for different currents for a) $\mathrm{LiMn}_{0.5} \mathrm{~V}_{0.5} \mathrm{O}_{2}$ and b) $\mathrm{LiCo} 0.5 \mathrm{~V}_{0.5} \mathrm{O}_{2}$. Corresponding voltage profiles for the initial cycles c) $\mathrm{LiMn} 0.5 \mathrm{~V}_{0.5} \mathrm{O}_{2}$ and d) $\mathrm{LiCo} 0.5 \mathrm{~V}_{0.5} \mathrm{O}_{2}$.

\section{Comparison of vanadium-based disordered rock-salts as positive electrode material}

Finally, to evaluate the performances of the presented materials with respect to other vanadium-based cation-disordered rock-salt oxides the respective capacities and energy densities have been compared in Figure 10. Most compounds show an average discharge 
voltage of about $2.5 \pm 0.3 \mathrm{~V}$, the exact value being influenced by the oxidation state and the second TM. However, as expected, Li-rich compositions tend to exhibit higher capacities and higher energy densities compared to the stoichiometric compounds.

The approaches to introduce lithium-excess can, in general, be divided into the modification of the cation and/or the anion sublattice. The first approach relies on higher-valent, electrochemically inactive charge compensators with mostly $\mathrm{d}^{0}$-elements such as $\mathrm{Nb}^{+5}, \mathrm{Ti}^{+4}$ and possibly $\mathrm{Mo}^{+6}$ and, interestingly, also with $\mathrm{d}^{1}$-elements such as $\mathrm{V}^{+4}$, which can offer additional transition metal redox capacity. Important to note, $\mathrm{V}^{+4}$ based disordered rock-salt compounds are only accessible by mechanochemical synthesis or are formed during cycling. ${ }^{31,59}$ The second approach relies on the fluorination of the anion-sublattice and can stabilize lower oxidation states as it has been demonstrated for $\mathrm{Li}_{2} \mathrm{M}^{+4} \mathrm{O}_{3} / \mathrm{Li}_{2} \mathrm{M}^{+3} \mathrm{O}_{2} \mathrm{~F}(\mathrm{M}=$ $\mathrm{Mn}, \mathrm{V}) .{ }^{60-62}$ Moreover, both concepts can be combined to design optimal compositions with high energy density.

Both $\mathrm{Li}_{2} \mathrm{VO}_{2} \mathrm{~F}$ and $\mathrm{Li}_{2} \mathrm{Cr}_{0.2} \mathrm{~V}_{0.8} \mathrm{O}_{2} \mathrm{~F}$ display a specific capacity between $360-420 \mathrm{mAh} \mathrm{g}^{-1}$ delivering energy densities between $900-1200 \mathrm{Wh} \mathrm{kg}^{-1}$ for the initial cycles indicating the advantage of multiple redox centers with $\mathrm{M}^{+3 /+5}$ oxidation state. Furthermore, the combination with high voltage $\mathrm{M}^{+2 /+4}$ couples can provide a more significant fraction of the capacity coming at higher voltage, thereby increasing the average discharge voltage as shown for $\mathrm{Li}_{1.23} \mathrm{Mn}_{0.255} \mathrm{~V}_{0.515} \mathrm{O}_{0.18} \mathrm{~F}_{0.2}$ and $\mathrm{Li}_{1.2} \mathrm{Mn}_{0.2} \mathrm{~V}_{0.6} \mathrm{O}_{2}$. Interesting is that the $\mathrm{LiMn}_{0.5} \mathrm{~V}_{0.5} \mathrm{O}_{2}$ presented here shows a lower average voltage as compared to the Li-rich compositions. This can partly be attributed to the lower oxidation state in the fluorinated compounds. $\begin{array}{rrr}\text { LiNi } & \mathrm{V} & \mathrm{O}\end{array}$ and LiCo $\mathrm{V}_{0.5} \underset{0.52}{\mathrm{O}} \mathrm{O}$ are crossing the $600 \mathrm{Wh} \mathrm{kg}^{-1}$ and promise higher energy density for Li-rich compositions. Fluorine substitution is the most promising approach as it allows the combination of low-value transition metal with excess lithium and thus reduces oxygen redox and/or oxygen loss, which adversely affects cell performance. The latter requires the oxidation to higher oxidations states, e.g., $\mathrm{M}^{+3 /+4}$, which tend to be unstable and often are 
accompanied by oxygen redox and oxygen loss leading to surface degradation. The combination of both approaches can alleviate this effect as the fraction of the transition metal redox could be increased. ${ }^{63}$

Starting from the here presented stoichiometric $\mathrm{LiM}_{0.5} \mathrm{~V}_{0.5} \mathrm{O}_{2}$ disordered rock-salt compounds, lithium-excess could be either introduced by basically changing towards vanadium-rich composition with $\mathrm{Li}_{1+2 \mathrm{x}} \mathrm{M}_{0.5-2 \mathrm{x}} \mathrm{V}_{0.5+\mathrm{x}} \mathrm{O}_{2}$. Furthermore, lithium-excess can be introduced through fluorination by introducing LiF with high energy milling or by forming solidsolutions by higher-valent elements. This can open the path for the design of optimized compositions, which can exhibit higher capacity and increased energy density.

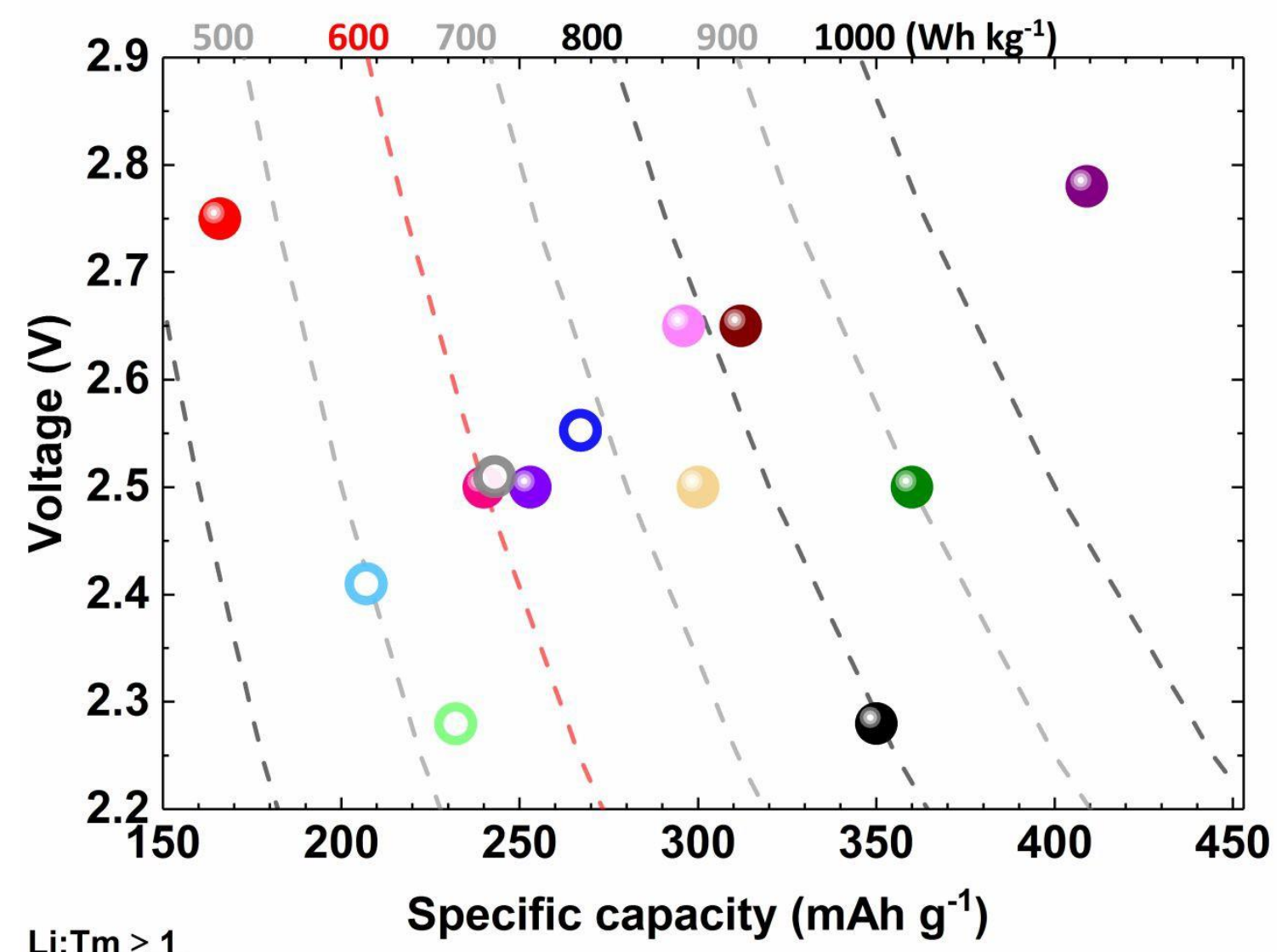

Li:Tm $\geq 1$
- $\mathrm{Li}_{1.3} \mathrm{Nb}_{0.3} \mathrm{~V}_{0.4} \mathrm{O}_{2}{ }^{(\mathrm{a})}$
- $\mathrm{Li}_{2} \mathrm{VO}_{2} \mathrm{~F}^{(\mathrm{b})}$
(- $\mathrm{Li}_{2} \mathrm{Cr}_{0.2} \mathrm{~V}_{0.8} \mathrm{O}_{2} \mathrm{~F}^{(\mathrm{c})}$
(- $\mathrm{Li}_{2-\mathrm{x}} \mathrm{VO}_{3}{ }^{(\mathrm{d})}$
(-) $\mathrm{Li}_{1.25} \mathrm{Nb}_{0.25} \mathrm{~V}_{0.5} \mathrm{O}_{2}{ }^{(\mathrm{e})}$
- $\omega-\mathrm{Li}_{3} \mathrm{~V}_{2} \mathrm{O}_{5}{ }^{(\mathrm{f})}$
(-) $\mathrm{Li}_{1.2} \mathrm{Mn}_{0.2} \mathrm{~V}_{0.6} \mathrm{O}_{2}{ }^{(\mathrm{e})}$
$\mathrm{Li}_{2-\mathrm{x}} \mathrm{VTiO}_{4}{ }^{(\mathrm{g})(\#)}$
$\mathrm{Li}_{1.23} \mathrm{Mn}_{0.255} \mathrm{~V}_{0.515} \mathrm{O}_{1.8} \mathrm{~F}_{0.2}{ }^{(\mathrm{e})}$

$\underline{\mathrm{Li}: \mathrm{Tm}} \leq 1$
(2) $\mathrm{LiNi}_{0.5} \mathrm{~V}_{0.5} \mathrm{O}_{2}{ }^{\text {(h) }}$
$\mathrm{LiCo}_{0.5} \mathrm{~V}_{0.5} \mathrm{O}_{2}{ }^{(h)}$
$\mathrm{LiFe}_{0.5} \mathrm{~V}_{0.5} \mathrm{O}_{2}^{(\mathrm{h})}$
$\mathrm{LiMn}_{0.5} \mathrm{~V}_{0.5} \mathrm{O}_{2}{ }^{(\mathrm{h})}$ 
Figure 10: Reported first discharge average voltage and specific capacity values for various vanadium-based ${ }^{13,31,50,59,64-67}$ stoichiometric and Li-rich cation disordered rock-salt oxides. The dashed lines (---) correspond to isoenergetic lines for specific energy densities ( $\left.\mathrm{Wh} \mathrm{kg}^{-1}\right)$. Footnotes show the cycling range (a) 4.8-1.5 V (b) 4.1-1.3 V (c) 4.7-1.3 V (d) 3.5-1.0 V (e) 4.6-1.5 V (f) 4.0-1.0 V (g) 4.4-1.0 V (h) 4.5-1.3 V. \# becomes Li-rich after first discharge.

\section{Summary \& Conclusion}

We have introduced a set of new ternary disordered rock-salt-type compounds with the general formula $\mathrm{LiM}_{0.5} \mathrm{~V}_{0.5} \mathrm{O}_{2}(\mathrm{M}=\mathrm{Fe}, \mathrm{Mn}, \mathrm{Co})$ as potential positive electrode materials in LiBs. The phases contain $\mathrm{V}^{+4}$ and $\mathrm{M}^{+2}$ redox centers, with the average oxidation state being +3 . We demonstrate that the electrochemical properties can effectively be tuned by substituting different transition metals in the host lattice. The reported average discharge voltage of the disordered rock-salt $\mathrm{Li}_{2} \mathrm{VO}_{3}\left(\mathrm{Li}_{1.333} \mathrm{~V}_{0.666} \mathrm{O}_{2}\right)$ with a $\mathrm{V}^{5+/ 4+}$ redox couple is 2.20 V. ${ }^{17}$ The ternary rock-salt $\mathrm{LiM}_{0.5} \mathrm{~V}_{0.5} \mathrm{O}_{2}(\mathrm{M}=\mathrm{Fe}, \mathrm{Mn}, \mathrm{Co})$, which can be thought as a hypothetical solid-solution between " $\mathrm{Li}_{2} \mathrm{VO}_{3}-\mathrm{MO}$ ” show higher average voltages as compared to $\mathrm{Li}_{2} \mathrm{VO}_{3}$, which increase in the order $\mathrm{Mn}<\mathrm{Fe}<\mathrm{Co}$ with $2.28,2.41,2.51 \mathrm{~V}$, demonstrating the beneficial effect of the cation substitution on the electrochemical properties.

LiMn $0.5 \mathrm{~V}_{0.5} \mathrm{O}_{2}$ and $\mathrm{LiCo} 0.5 \mathrm{~V}_{0.5} \mathrm{O}_{2}$ cycled between $4.5-1.3 \mathrm{~V}$ exhibit a specific discharge capacity of 219 and $234 \mathrm{mAh} \mathrm{g}^{-1}$ at $20 \mathrm{~mA} \mathrm{~g}^{-1}$, respectively. The capacity retention increases progressively by reducing the voltage window but comes at the cost of lower specific capacity. The low apparent diffusion coefficients of $\mathrm{LiCo} 0.5 \mathrm{~V}_{0.5} \mathrm{O}_{2}$ and $\mathrm{LiMn}_{0.5} \mathrm{~V}_{0.5} \mathrm{O}_{2}$ necessitate the use of nanoscale materials in order to achieve high delithiation degrees with acceptable rate capability. We, therefore, argue that mechanochemical synthesis can be beneficial as it is an advantageous alternative to traditional nanomaterial preparation. The small changes in the lattice constant during lithiation/delithiation could be associated with a structural distortion and possibly due to transition metal migration from octahedral to face-shared tetrahedral sites during the charging process. This may deteriorate the diffusion kinetics and inhibit lithium 
insertion/extraction as an additional source of performance degradation. Furthermore, performance deterioration could partly be attributed to metal dissolution and migration from the positive electrode and deposition on the lithium electrode. A dissolution study revealed that dissolution of the active material increases by at least one order of magnitude for the charged state; however, the resulting active material loss cannot account for the significant capacity loss. We, therefore, conclude that electrode/electrolyte side reactions and cation migration are predominant for the capacity loss. This is supported by the fact that switching from 1.0 M LiPF6 (EC:DMC 1:1 w/w) electrolyte to a concentrated 5.5 M lithium bis(fluorosulfonyl) imide (LiFSI) in DMC as electrolyte increased the capacity retention by a factor of 1.4 and 1.8 at the end of 400 cycles for $\operatorname{LiCo} 0.5 \mathrm{~V}_{0.5} \mathrm{O}_{2}$ and $\mathrm{LiMn}_{0.5} \mathrm{~V}_{0.5} \mathrm{O}_{2}$, respectively. The compounds presented here could be evaluated as a set of basis cathode materials and enabling us for further tuning and optimizations in the direction of lithiumexcess compositions. This could be realized by either changing towards vanadium-rich compositions with $\mathrm{Li}_{1+2 \times} \mathrm{M}_{0.5-2 \times} \mathrm{V}_{0.5+\mathrm{x}} \mathrm{O}_{2}$ or/and fluorination to $\mathrm{Li}_{2}(\mathrm{M}, \mathrm{V}) \mathrm{O}_{2}$ F oxyfluoride.

\section{Acknowledgment:}

Financial support by the FET-OPEN project "LiRichFCC" of the European Commission (grant agreement \# 711792) is gratefully acknowledged. This work contributes to the research performed at CELEST (Center for Electrochemical Energy Storage Ulm-Karlsruhe).We acknowledge Rune E. Johnsen for the synchrotron measurements and help with the analysis. The staff at beamline BM01, SNBL/ESRF, is greatly acknowledged for experimental assistance. 


\section{Literature:}

(1) Rozier, P.; Tarascon, J. M. Review-Li-rich Layered Oxide Cathodes for NextGeneration Li-Ion Batteries: Chances and Challenges. J. Electrochem. Soc. 2015, 162 (14), A2490-A2499. https://doi.org/10.1149/2.0111514jes.

(2) Whittingham, M. S. Lithium Batteries and Cathode Materials. Chem. Rev. 2004, 104 (10), 4271-4301. https://doi.org/10.1088/1751-8113/44/8/085201.

(3) Etacheri, V.; Marom, R.; Elazari, R.; Salitra, G.; Aurbach, D. Challenges in the Development of Advanced Li-Ion Batteries: A Review. Energy Environ. Sci. 2011, 4 (9), 3243. https://doi.org/10.1039/c1ee01598b.

(4) Nitta, N.; Wu, F.; Lee, J. T.; Yushin, G. Li-Ion Battery Materials: Present and Future. Mater. Today 2015, 18 (5), 252-264. https://doi.org/10.1016/j.mattod.2014.10.040.

(5) Park, M.; Zhang, X.; Chung, M.; Less, G. B.; Sastry, A. M. A Review of Conduction Phenomena in Li-Ion Batteries. J. Power Sources 2010, 195 (24), 7904-7929. https://doi.org/10.1016/j.jpowsour.2010.06.060.

(6) Li, H. H.; Yabuuchi, N.; Meng, Y. S.; Kumar, S.; Breger, J.; Grey, C. P.; Shao-Horn, Y. Changes in the Cation Ordering of Layered O3 LixNi0.5Mn0.5O2during Electrochemical Cycling to High Voltages: An Electron Diffraction Study. Chem. Mater. 2007. https://doi.org/10.1021/cm070139+.

(7) Seymour, I. D.; Wales, D. J.; Grey, C. P. Preventing Structural Rearrangements on Battery Cycling: A First-Principles Investigation of the Effect of Dopants on the Migration Barriers in Layered Li0.5MnO2. J. Phys. Chem. C 2016, 120 (35), 1952119530. https://doi.org/10.1021/acs.jpcc.6b05307.

(8) Thackeray, M. M. From Gems to Lithium Battery Electrodes: The Significance of the Diamond, Ruby (Sapphire), Spinel and Peridot Structures. J. Power Sources 2001, 9798, 7-12. https://doi.org/10.1016/S0378-7753(01)00503-1.

(9) Sun, Y.-K.; Myung, S.-T.; Park, B.-C.; Prakash, J.; Belharouak, I.; Amine, K. High- 
Energy Cathode Material for Long-Life and Safe Lithium Batteries. Nat. Mater. 2009, 8 (4), 320-324. https://doi.org/10.1038/nmat2418.

(10) Urban, A.; Lee, J.; Ceder, G. The Configurational Space of Rocksalt-Type Oxides for High-Capacity Lithium Battery Electrodes. Adv. Energy Mater. 2014, 4 (13), 1400478. https://doi.org/10.1002/aenm.201400478.

(11) Lee, J.; Urban, A.; Li, X.; Su, D.; Hautier, G.; Ceder, G. Unlocking the Potential of Cation-Disordered Oxides for Rechargeable Lithium Batteries. Science (80-. ). 2014, 343 (6170), 519-522. https://doi.org/10.1126/science.1246432.

(12) Sun, Y.-K.; Chen, Z.; Noh, H.-J.; Lee, D.-J.; Jung, H.-G.; Ren, Y.; Wang, S.; Yoon, C. S.; Myung, S.-T.; Amine, K. Nanostructured High-Energy Cathode Materials for Advanced Lithium Batteries. Nat. Mater. 2012, 11 (11), 942-947. https://doi.org/10.1038/nmat3435.

(13) Chen, R.; Ren, S.; Knapp, M.; Wang, D.; Witter, R.; Fichtner, M.; Hahn, H. Disordered Lithium-Rich Oxyfluoride as a Stable Host for Enhanced Li + Intercalation Storage. Adv. Energy Mater. 2015, 5 (9), 1401814. https://doi.org/10.1002/aenm.201401814.

(14) Lee, J.; Seo, D.-H.; Balasubramanian, M.; Twu, N.; Li, X.; Ceder, G. A New Class of High Capacity Cation-Disordered Oxides for Rechargeable Lithium Batteries: Li-NiTi-Mo Oxides. Energy Environ. Sci. 2015, 8 (11), 3255-3265. https://doi.org/10.1039/C5EE02329G.

(15) Yabuuchi, N.; Takeuchi, M.; Nakayama, M.; Shiiba, H.; Ogawa, M.; Nakayama, K.; Ohta, T.; Endo, D.; Ozaki, T.; Inamasu, T.; et al. High-Capacity Electrode Materials for Rechargeable Lithium Batteries: Li3NbO4 -Based System with Cation-Disordered Rocksalt Structure. Proc. Natl. Acad. Sci. 2015, 112 (25), 7650-7655. https://doi.org/10.1073/pnas.1504901112.

(16) Ren, S.; Chen, R.; Maawad, E.; Dolotko, O.; Guda, A. A.; Shapovalov, V.; Wang, D.; Hahn, H.; Fichtner, M. Improved Voltage and Cycling for Li + Intercalation in High- 
Capacity Disordered Oxyfluoride Cathodes. Adv. Sci. 2015, 2 (10), 1500128. https://doi.org/10.1002/advs.201500128.

(17) Chen, R.; Ren, S.; Yavuz, M.; Guda, A. A.; Shapovalov, V.; Witter, R.; Fichtner, M.; Hahn, $\mathrm{H} . \mathrm{Li}^{+}$Intercalation in Isostructural $\mathrm{Li}_{2} \mathrm{VO}_{3}$ and $\mathrm{Li}_{2} \mathrm{VO}_{2} \mathrm{~F}$ with $\mathrm{O}^{2-}$ and Mixed $\mathrm{O}^{2-} / \mathrm{F}^{-}$Anions. Phys. Chem. Chem. Phys. 2015, 17 (26), 17288-17295. https://doi.org/10.1039/C5CP02505B.

(18) Glazier, S. L.; Li, J.; Zhou, J.; Bond, T.; Dahn, J. R. Characterization of Disordered $\mathrm{Li}_{(1+\mathrm{x})} \mathrm{Ti}_{2 \mathrm{x}} \mathrm{Fe}_{(1-3 \mathrm{x})} \mathrm{O}_{2}$ as Positive Electrode Materials in Li-Ion Batteries Using Percolation Theory. Chem. Mater. 2015, 27 (22), 7751-7756. https://doi.org/10.1021/acs.chemmater.5b03530.

(19) Gilbert, J. A.; Shkrob, I. A.; Abraham, D. P. Transition Metal Dissolution, Ion Migration, Electrocatalytic Reduction and Capacity Loss in Lithium-Ion Full Cells. $J$. Electrochem. Soc. 2017, 164 (2), A389-A399. https://doi.org/10.1149/2.1111702jes.

(20) Schipper, F.; Bouzaglo, H.; Dixit, M.; Erickson, E. M.; Weigel, T.; Talianker, M.; Grinblat, J.; Burstein, L.; Schmidt, M.; Lampert, J.; et al. From Surface ZrO2 Coating to Bulk Zr Doping by High Temperature Annealing of Nickel-Rich Lithiated Oxides and Their Enhanced Electrochemical Performance in Lithium Ion Batteries. Adv. Energy Mater. 2018, 8 (4), 1701682. https://doi.org/10.1002/aenm.201701682.

(21) Chen, Z.; Qin, Y.; Amine, K.; Sun, Y.-K. Role of Surface Coating on Cathode Materials for Lithium-Ion Batteries. J. Mater. Chem. 2010, 20 (36), 7606. https://doi.org/10.1039/c0jm00154f.

(22) Lu, J.; Zhan, C.; Wu, T.; Wen, J.; Lei, Y.; Kropf, A. J.; Wu, H.; Miller, D. J.; Elam, J. W.; Sun, Y.-K.; et al. Effectively Suppressing Dissolution of Manganese from Spinel Lithium Manganate via a Nanoscale Surface-Doping Approach. Nat. Commun. 2014, 5 (1), 5693. https://doi.org/10.1038/ncomms6693.

(23) Aurbach, D.; Gamolsky, K.; Markovsky, B.; Gofer, Y.; Schmidt, M.; Heider, U. On the 
Use of Vinylene Carbonate (VC) as an Additive to Electrolyte Solutions for Li-Ion Batteries. Electrochim. Acta 2002. https://doi.org/10.1016/S0013-4686(01)00858-1.

(24) $\mathrm{Xu}, \mathrm{K}$. Electrolytes and Interphases in Li-Ion Batteries and Beyond. Chem. Rev. 2014, 114 (23), 11503-11618. https://doi.org/10.1021/cr500003w.

(25) Yang, H.; Kwon, K.; Devine, T. M.; Evans, J. W. Aluminum Corrosion in Lithium Batteries An Investigation Using the Electrochemical Quartz Crystal Microbalance. $J$. Electrochem. Soc. 2000, 147 (12), 4399. https://doi.org/10.1149/1.1394077.

(26) Zaghib, K.; Charest, P.; Guerfi, A.; Shim, J.; Perrier, M.; Striebel, K. Safe Li-Ion Polymer Batteries for HEV Applications. J. Power Sources 2004. https://doi.org/10.1016/j.jpowsour.2004.02.020.

(27) Zaghib, K.; Charest, P.; Guerfi, A.; Shim, J.; Perrier, M.; Striebel, K. LiFePO4 Safe LiIon Polymer Batteries for Clean Environment. In Journal of Power Sources; 2005. https://doi.org/10.1016/j.jpowsour.2005.03.141.

(28) Abouimrane, A.; Ding, J.; Davidson, I. J. Liquid Electrolyte Based on Lithium BisFluorosulfonyl Imide Salt: Aluminum Corrosion Studies and Lithium Ion Battery Investigations. J. Power Sources 2009, 189 (1), 693-696. https://doi.org/10.1016/j.jpowsour.2008.08.077.

(29) Yamada, Y.; Yamada, A. Review-Superconcentrated Electrolytes for Lithium Batteries. J. Electrochem. Soc. 2015, 162 (14), A2406-A2423. https://doi.org/10.1149/2.0041514jes.

(30) Wang, J.; Yamada, Y.; Sodeyama, K.; Chiang, C. H.; Tateyama, Y.; Yamada, A. Superconcentrated Electrolytes for a High-Voltage Lithium-Ion Battery. Nat. Commun. 2016, 7 (1), 12032. https://doi.org/10.1038/ncomms12032.

(31) Cambaz, M. A.; Vinayan, B. P.; Euchner, H.; Johnsen, R. E.; Guda, A. A.; Mazilkin, A.; Rusalev, Y. V; Trigub, A. L.; Gross, A.; Fichtner, M. Design of Nickel-Based Cation-Disordered Rock-Salt Oxides: The Effect of Transition Metal (M = V, Ti, Zr) 
Substitution in LiNi0.5M0.5O2 Binary Systems. ACS Appl. Mater. Interfaces 2018, 10 (26), 21957-21964. https://doi.org/10.1021/acsami.8b02266.

(32) Brauer, G. Handbook of Preparative Inorganic Chemistry. Acad. Press (New York, N.Y.) 1965, 144 (3619), 703. https://doi.org/10.1126/science.144.3619.703-a.

(33) Hammersley, A. P.; Svensson, S. O.; Hanfland, M.; Fitch, A. N.; Hausermann, D. TwoDimensional Detector Software: From Real Detector to Idealised Image or Two-Theta Scan. High Press. Res. 1996, 14 (4-6), 235-248. https://doi.org/10.1080/08957959608201408.

(34) Urban, A.; Matts, I.; Abdellahi, A.; Ceder, G. Computational Design and Preparation of Cation-Disordered Oxides for High-Energy-Density Li-Ion Batteries. Adv. Energy Mater. 2016, 6 (15), 1600488. https://doi.org/10.1002/aenm.201600488.

(35) Cambaz, M. A.; Vinayan, B. P.; Clemens, O.; Munnangi, A. R.; Chakravadhanula, V. S. K.; Kübel, C.; Fichtner, M. Vanadium Oxyfluoride/Few-Layer Graphene Composite as a High-Performance Cathode Material for Lithium Batteries. Inorg. Chem. 2016, 55 (8), 3789-3796. https://doi.org/10.1021/acs.inorgchem.5b02687.

(36) Kresse, G.; Furthmüller, J. Efficient Iterative Schemes for Ab Initio Total-Energy Calculations Using a Plane-Wave Basis Set. Phys. Rev. B 1996, 54 (16), 11169-11186. https://doi.org/10.1103/PhysRevB.54.11169.

(37) Perdew, J. P.; Burke, K.; Ernzerhof, M. Generalized Gradient Approximation Made Simple. Phys. Rev. Lett. 1996. https://doi.org/10.1103/PhysRevLett.77.3865.

(38) Kresse, G.; Joubert, D. From Ultrasoft Pseudopotentials to the Projector AugmentedWave Method. Phys. Rev. B 1999, 59 (3), 1758-1775. https://doi.org/10.1103/PhysRevB.59.1758.

(39) Zunger, A.; Wei, S.-H.; Ferreira, L. G.; Bernard, J. E. Special Quasirandom Structures. Phys. Rev. Lett. 1990, 65 (3), 353-356. https://doi.org/10.1103/PhysRevLett.65.353.

(40) Yabuuchi, N.; Nakayama, M.; Takeuchi, M.; Komaba, S.; Hashimoto, Y.; Mukai, T.; 
Shiiba, H.; Sato, K.; Kobayashi, Y.; Nakao, A.; et al. Origin of Stabilization and Destabilization in Solid-State Redox Reaction of Oxide Ions for Lithium-Ion Batteries. Nat. Commun. 2016. https://doi.org/10.1038/ncomms13814.

(41) Jacquet, Q.; Iadecola, A.; Saubanère, M.; Li, H.; Berg, E. J.; Rousse, G.; Cabana, J.; Doublet, M.-L.; Tarascon, J.-M. Charge Transfer Band Gap as an Indicator of Hysteresis in Li-Disordered Rock Salt Cathodes for Li-Ion Batteries. J. Am. Chem. Soc. 2019. https://doi.org/10.1021/jacs.8b11413.

(42) Terada, Y.; Yasaka, K.; Nishikawa, F.; Konishi, T.; Yoshio, M.; Nakai, I. In Situ XAFS Analysis of Li(Mn, M)2O4 (M=Cr, Co, Ni) 5V Cathode Materials for LithiumIon Secondary Batteries. J. Solid State Chem. 2001, 156 (2), 286-291. https://doi.org/10.1006/jssc.2000.8990.

(43) Lun, Z.; Ouyang, B.; Kitchaev, D. A.; Clément, R. J.; Papp, J. K.; Balasubramanian, M.; Tian, Y.; Lei, T.; Shi, T.; McCloskey, B. D.; et al. Improved Cycling Performance of Li-Excess Cation-Disordered Cathode Materials upon Fluorine Substitution. $A d v$. Energy Mater. 2019, 9 (2), 1802959. https://doi.org/10.1002/aenm.201802959.

(44) Assat, G.; Delacourt, C.; Corte, D. A. D.; Tarascon, J.-M. Editors' Choice—Practical Assessment of Anionic Redox in Li-Rich Layered Oxide Cathodes: A Mixed Blessing for High Energy Li-Ion Batteries. J. Electrochem. Soc. 2016, 163 (14), A2965-A2976. https://doi.org/10.1149/2.0531614jes.

(45) Goodenough, J. B. Review Lecture: Fast Ionic Conduction in Solids. Proc. R. Soc. A Math. Phys. Eng. Sci. 1984, 393 (1805), 215-234.

https://doi.org/10.1098/rspa.1984.0055.

(46) Cambaz, M. A.; Anji Reddy, M.; Vinayan, B. P.; Witte, R.; Pohl, A.; Mu, X.; Chakravadhanula, V. S. K.; Kübel, C.; Fichtner, M. Mechanical Milling Assisted Synthesis and Electrochemical Performance of High Capacity LiFeBO 3 for Lithium Batteries. ACS Appl. Mater. Interfaces 2016, 8 (3), 2166-2172. 
https://doi.org/10.1021/acsami.5b10747.

(47) Augustyn, V.; Come, J.; Lowe, M. A.; Kim, J. W.; Taberna, P.-L.; Tolbert, S. H.;

Abruña, H. D.; Simon, P.; Dunn, B. High-Rate Electrochemical Energy Storage through Li+ Intercalation Pseudocapacitance. Nat. Mater. 2013, 12 (6), 518-522. https://doi.org/10.1038/nmat3601.

(48) Shannon, R. D. Revised Effective Ionic Radii and Systematic Studies of Interatomic Distances in Halides and Chalcogenides. Acta Crystallogr. Sect. A 1976, 32 (5), 751767. https://doi.org/10.1107/S0567739476001551.

(49) Diaz-Lopez, M.; Freire, M.; Joly, Y.; Colin, C. V.; Fischer, H. E.; Blanc, N.; Boudet, N.; Pralong, V.; Bordet, P. Local Structure and Lithium Diffusion Pathways in Li4Mn2O5 High Capacity Cathode Probed by Total Scattering and XANES. Chem. Mater. 2018, 30 (9), 3060-3070. https://doi.org/10.1021/acs.chemmater.8b00827.

(50) Nakajima, M.; Yabuuchi, N. Lithium-Excess Cation-Disordered Rocksalt-Type Oxide with Nanoscale Phase Segregation: Li1.25 $\mathrm{Nb}_{0.25} \mathrm{~V}_{0.5} \mathrm{O}_{2}$. Chem. Mater. 2017, 29 (16), 6927-6935. https://doi.org/10.1021/acs.chemmater.7b02343.

(51) MacNeil, D. D.; Dahn, J. R. The Reaction of Charged Cathodes with Nonaqueous Solvents and Electrolytes: II. LiMn2O4 Charged to 4.2 V. J. Electrochem. Soc. 2001, 148 (11), A1211. https://doi.org/10.1149/1.1407246.

(52) Choi, S.; Manthiram, A. Designing Structurally Stable Layered Oxide Cathodes for Lithium-Ion Batteries. Mater. Electrochem. Energy Convers. Storage 2002.

(53) Cambaz, M. A.; Vinayan, B. P.; Clemens, O.; Munnangi, A. R.; Chakravadhanula, V. S. K.; Kübel, C.; Fichtner, M. Vanadium Oxyfluoride/Few-Layer Graphene Composite as a High-Performance Cathode Material for Lithium Batteries. Inorg. Chem. 2016, 55 (8), 3789-3796. https://doi.org/10.1021/acs.inorgchem.5b02687.

(54) Aurbach, D.; Gamolsky, K.; Markovsky, B.; Gofer, Y.; Schmidt, M.; Heider, U. On the Use of Vinylene Carbonate (VC) as an Additive to Electrolyte Solutions for Li-Ion 
Batteries. Electrochim. Acta 2002, 47 (9), 1423-1439. https://doi.org/10.1016/S00134686(01)00858-1.

(55) Ma, L.; Xia, J.; Xia, X.; Dahn, J. R. The Impact of Vinylene Carbonate, Fluoroethylene Carbonate and Vinyl Ethylene Carbonate Electrolyte Additives on Electrode/Electrolyte Reactivity Studied Using Accelerating Rate Calorimetry. J.

Electrochem. Soc. 2014. https://doi.org/10.1149/2.0091410jes.

(56) Wang, D. Y.; Xiao, A.; Wells, L.; Dahn, J. R. Effect of Mixtures of Lithium Hexafluorophosphate (LiPF 6 ) and Lithium Bis(Fluorosulfonyl)Imide (LiFSI) as Salts in Li[Ni 1/3 Mn 1/3 Co 1/3 ]O 2 /Graphite Pouch Cells. J. Electrochem. Soc. 2015, 162 (1), A169-A175. https://doi.org/10.1149/2.0821501jes.

(57) Han, H.-B.; Zhou, S.-S.; Zhang, D.-J.; Feng, S.-W.; Li, L.-F.; Liu, K.; Feng, W.-F.; Nie, J.; Li, H.; Huang, X.-J. Lithium Bis(Fluorosulfonyl)Imide (LiFSI) as Conducting Salt for Nonaqueous Liquid Electrolytes for Lithium-Ion Batteries: Physicochemical and Electrochemical Properties. J. Power Sources 2011, 196 (7), 3623-3632. https://doi.org/10.1016/j.jpowsour.2010.12.040.

(58) YAMADA, Y. Developing New Functionalities of Superconcentrated Electrolytes for Lithium-Ion Batteries. Electrochemistry 2017, 85 (9), 559-565. https://doi.org/10.5796/electrochemistry.85.559.

(59) Pralong, V.; Gopal, V.; Caignaert, V.; Duffort, V.; Raveau, B. Lithium-Rich Rock-SaltType Vanadate as Energy Storage Cathode: Li2- XVO3. Chem. Mater. 2012, 24 (1), 12-14. https://doi.org/10.1021/cm203281q.

(60) Chen, R.; Ren, S.; Yavuz, M.; Guda, A. A.; Shapovalov, V.; Witter, R.; Fichtner, M.; Hahn, H. Li + Intercalation in Isostructural Li 2 VO 3 and Li 2 VO 2 F with O 2- and Mixed O 2-/F - Anions. Phys. Chem. Chem. Phys. 2015, 17 (26), 17288-17295. https://doi.org/10.1039/C5CP02505B.

(61) House, R. A.; Jin, L.; Maitra, U.; Tsuruta, K.; Somerville, J. W.; Förstermann, D. P.; 
Massel, F.; Duda, L.; Roberts, M. R.; Bruce, P. G. Lithium Manganese Oxyfluoride as a New Cathode Material Exhibiting Oxygen Redox. Energy Environ. Sci. 2018, 11 (4), 926-932. https://doi.org/10.1039/C7EE03195E.

(62) Freire, M.; Lebedev, O. I.; Maignan, A.; Jordy, C.; Pralong, V. Nanostructured Li2MnO3 : A Disordered Rock Salt Type Structure for High Energy Density Li Ion Batteries. J. Mater. Chem. A 2017, 5 (41), 21898-21902. https://doi.org/10.1039/C7TA07476J.

(63) Lee, J.; Papp, J. K.; Clément, R. J.; Sallis, S.; Kwon, D.-H.; Shi, T.; Yang, W.; McCloskey, B. D.; Ceder, G. Mitigating Oxygen Loss to Improve the Cycling Performance of High Capacity Cation-Disordered Cathode Materials. Nat. Commun. 2017, 8 (1), 981. https://doi.org/10.1038/s41467-017-01115-0.

(64) Yabuuchi, N.; Takeuchi, M.; Komaba, S.; Ichikawa, S.; Ozaki, T.; Inamasu, T. Synthesis and Electrochemical Properties of Li1.3Nb0.3V0.4O2 as a Positive Electrode Material for Rechargeable Lithium Batteries. Chem. Commun. 2016, 52 (10), 20512054. https://doi.org/10.1039/C5CC08034G.

(65) Kitchaev, D. A.; Lun, Z.; Richards, W. D.; Ji, H.; Clément, R. J.; Balasubramanian, M.; Kwon, D.-H.; Dai, K.; Papp, J. K.; Lei, T.; et al. Design Principles for High Transition Metal Capacity in Disordered Rocksalt Li-Ion Cathodes. Energy Environ. Sci. 2018, 11 (8), 2159-2171. https://doi.org/10.1039/C8EE00816G.

(66) Delmas, C.; Brèthes, S.; Ménétrier, M. $\omega$-LixV2O5 — a New Electrode Material for Rechargeable Lithium Batteries. J. Power Sources 1991, 34 (2), 113-118. https://doi.org/10.1016/0378-7753(91)85030-Z.

(67) Dominko, R.; Garrido, C. V.-A.; Bele, M.; Kuezma, M.; Arcon, I.; Gaberscek, M. Electrochemical Characteristics of Li2-xVTiO4 Rock Salt Phase in Li-Ion Batteries. $J$. Power Sources 2011, 196 (16), 6856-6862.

https://doi.org/10.1016/j.jpowsour.2010.09.004. 


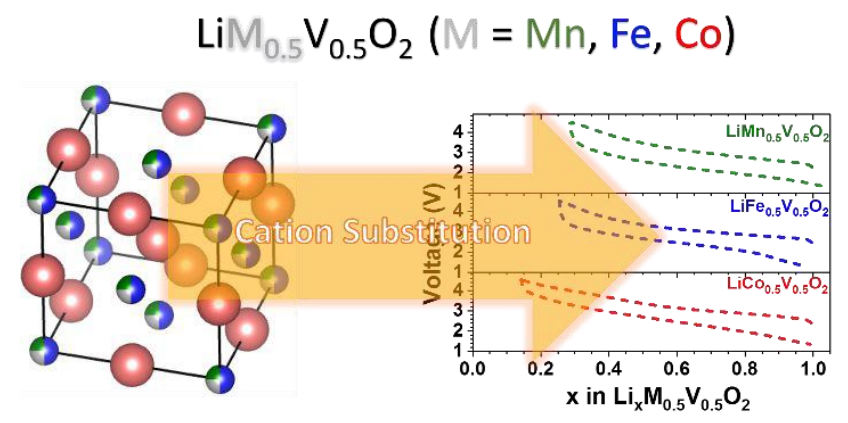

10

11

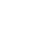

(1)

(1)

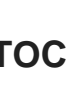

(

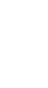

.

.

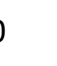

2

5

7

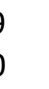

3

